\title{
Liquid-Like Grain Boundary Complexion and Sub-Eutectic Activated Sintering in CuO-Doped $\mathrm{TiO}_{2}$
}

\author{
Jiuyuan Nie, Jonathan M. Chan, Mingde Qin, Naixie Zhou, and Jian Luo* \\ Department of NanoEngineering, University of California, San Diego, La Jolla, CA 92093
}

\begin{abstract}
:
The eutectic temperature and composition of the $\mathrm{TiO}_{2}-\mathrm{CuO}$ system were carefully measured to be $1010 \pm 10{ }^{\circ} \mathrm{C}$ and $83 \mathrm{CuO}: 17 \mathrm{TiO}_{2}$, respectively. Subsequently, a $\mathrm{TiO}_{2}-\mathrm{CuO}$ phase diagram was computed, representing a correction and major improvement from the phase diagram available in literature. Dilatometry measurements and isothermal sintering experiments unequivocally demonstrated the activated (enhanced) sintering of $\mathrm{TiO}_{2}$ with the addition of $\mathrm{CuO}$, occurring at as low as $>300^{\circ} \mathrm{C}$ below the eutectic temperature. High resolution transmission electron microscopy (HRTEM) characterization of water-quenched specimens revealed the formation of nanometer-thick, liquid-like, intergranular films (IGFs), a type of grain boundary (GB) complexion (a.k.a. 2-D interfacial phase), concurrently with accelerated densification and well below the bulk eutectic temperature. Consequently, activated sintering is explained from the enhanced mass transport in this premelting-like complexion. An interfacial thermodynamic model was used to quantitatively explain and justify the stabilization of liquid-like IGFs below the eutectic temperature and the temperature-dependent IGF thicknesses measured by HRTEM. A GB $\lambda$ diagram was computed, for the first time for a ceramic system, to represent the thermodynamic tendency for general GBs in CuO-doped $\mathrm{TiO}_{2}$ to disorder.
\end{abstract}

Keywords: $\mathrm{TiO}_{2}-\mathrm{CuO}$ phase diagram; eutectic reaction; activated sintering; intergranular film; complexion

*Corresponding author. E-mail address: jluo@alum.mit.edu (J. Luo). 


\section{Graphical Abstract}

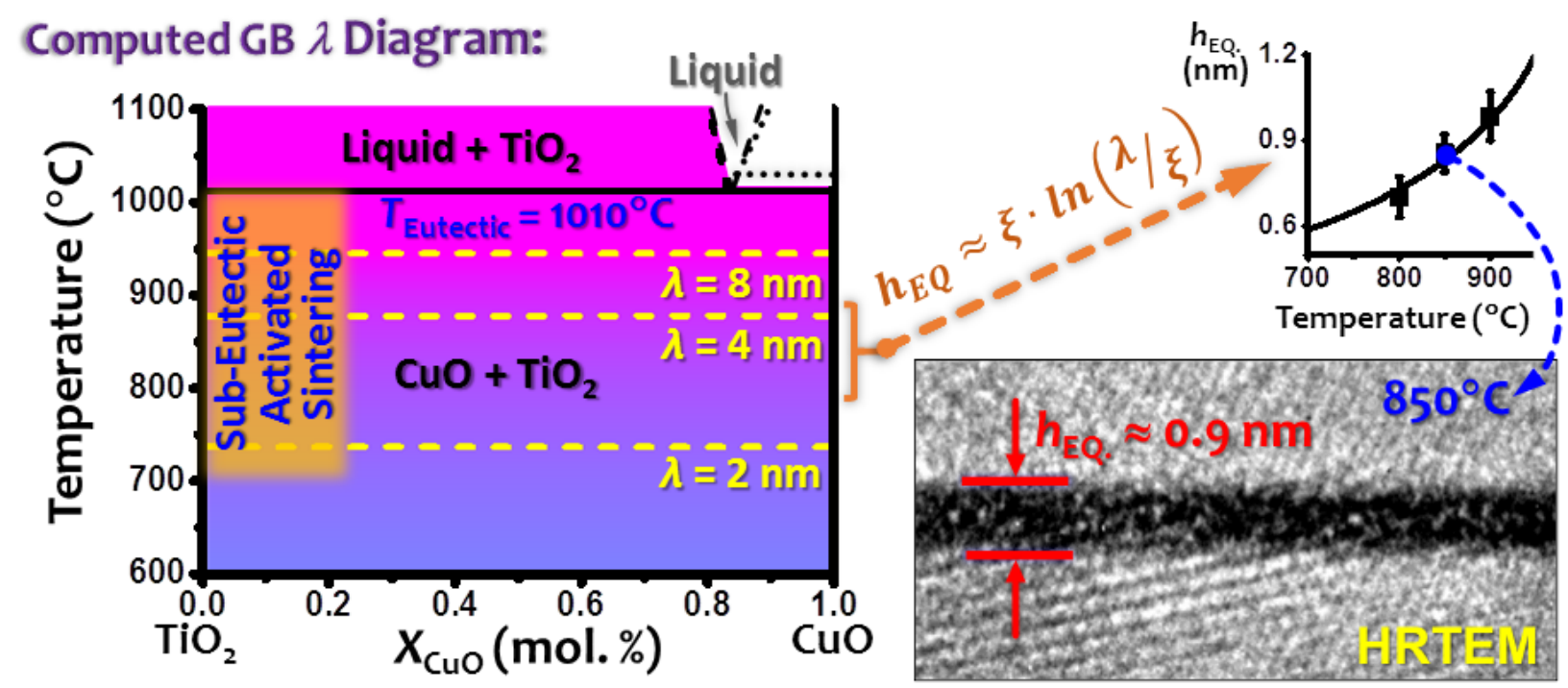




\section{Introduction}

Titania $\left(\mathrm{TiO}_{2}\right)$ has excellent electronic and optical properties that enable its applications in photovoltaic, sensing, and a variety of other types of devices (where some levels of low-temperature sintering are often involved) [1-3]. Furthermore, $\mathrm{TiO}_{2}$ has excellent dielectric properties for possible applications in electronics; however, the high sintering temperatures of pure $\mathrm{TiO}_{2}$, which are generally in the range of $1200-1400^{\circ} \mathrm{C}$ [4], make it incompatible with the low-temperature co-fired technology [5] that requires the sintering temperature to be appreciably lower than the melting temperature of the metal conductors, such as $\mathrm{Cu}\left(T_{\mathrm{m}}=1083^{\circ} \mathrm{C}\right)$ and $\mathrm{Ag}$ $\left(T_{\mathrm{m}}=961^{\circ} \mathrm{C}\right)[6]$. Thus, researchers have made great efforts to lower the sintering temperature of $\mathrm{TiO}_{2}$, e.g., via using monodisperse $\mathrm{TiO}_{2}$ powder [7] or making sol-gel films [8]. A more common and practical method is to add a small amount of sintering aids to lower the sintering temperature [9]. While $\mathrm{CuO}$ is perhaps one of the most effective sintering aid for promoting low-temperature densification of $\mathrm{TiO}_{2}[10,11]$, its exact underlying mechanisms remain elusive, which motivated this study.

It is well known that $\mathrm{CuO}$ doping can reduce the sintering temperatures of $\mathrm{TiO}_{2}$ to $\sim 850-950^{\circ} \mathrm{C}$, which was generally attributed to a liquid-phase sintering effect in prior studies [10, 12, 13]. However, Lu et al reported a computed eutectic temperature of $919^{\circ} \mathrm{C}$ for the $\mathrm{TiO}_{2}-\mathrm{CuO}$ system [14]. Recently, de la Rubia et al suggested that the eutectic temperature is $\sim 1000^{\circ} \mathrm{C}$ via differential scanning calorimetry (DSC) and thermogravimetric (TG) analysis, in conjunction with hot-stage microscopy [15]. These results casted doubt on the previously-hypothesized liquid-phase sintering mechanism for $\mathrm{CuO}$-doped $\mathrm{TiO}_{2}$, since the significant densification appeared to occur well below the eutectic temperature, though what is the exact/real eutectic temperature was still controversial prior to this study.

In this study, we conducted careful experiments to unequivocally showed that the low-temperature densification of $\mathrm{CuO}$-doped $\mathrm{TiO}_{2}$ is a case of sub-eutectic activated sintering, rather than the commonly-believed liquid-phase sintering. First, we measured the eutectic 
temperature and composition of the $\mathrm{CuO}-\mathrm{TiO}_{2}$ system via calibrating the furnace and characterizing well-quenched specimens. Specifically, we showed that the eutectic reaction takes place between $1000^{\circ} \mathrm{C}$ and $1020^{\circ} \mathrm{C}$ in air and determined the eutectic composition to be 83CuO: $17 \mathrm{TiO}_{2}$. Subsequently, we showed that enhanced densification can start below $700-800^{\circ} \mathrm{C}$, well below the bulk eutectic temperature. Furthermore, we observed the stabilization of nanoscale liquid-like intergranular films (IGFs) well below the bulk eutectic temperature by high resolution transmission electron microscopy (HRTEM) and attributed the sub-eutectic activated sintering in $\mathrm{CuO}-\mathrm{TiO}_{2}$ to the enhanced mass transport in this nanoscale liquid-like complexion (a.k.a. 2-D interfacial phase) that is stabilized below the eutectic temperature at grain boundaries (GBs), analogous those reported previously for $\mathrm{Bi}_{2} \mathrm{O}_{3}$-doped $\mathrm{ZnO}$ [16] and Ni-doped W and Mo [17-19].

Furthermore, we have computed a binary phase diagram for the $\mathrm{TiO}_{2}-\mathrm{CuO}$ system, which represents a major improvement from (and a correction of) the phase diagram available in literature. Subsequently, a GB $\lambda$ diagram was also computed to represent the thermodynamic tendency for general $\mathrm{GBs}$ in $\mathrm{CuO}$-doped $\mathrm{TiO}_{2}$ to disorder, for the first time for any ceramic system. We adopted an interfacial thermodynamic model to quantitively explain the stabilization of liquid-like IGFs below the bulk eutectic temperature, and to further justify the temperature-dependence of the IGF thicknesses measured by HRTEM.

\section{Experiments}

To determine the eutectic temperature and composition, rutile-phase $\mathrm{TiO}_{2}(99.9+\%$, purchased from US research Nanomaterials, Inc.) was mixed with $\mathrm{CuO}$ powder $(99.999 \%$, purchase from Sigma-Aldrich) in a mortar. The mixed powder was uniaxially compressed to pellets at $450 \mathrm{MPa}$. The surfaces of the pellets were slightly grinded to remove any contamination from the dies. The pellets were then placed in small sapphire crucibles $(>99.9 \%$ purity, purchased from AdValue Technology), annealed isothermally at desired temperatures (with a heating ramping rate of $5^{\circ} \mathrm{C} / \mathrm{min}$ before reaching the desired isothermal annealing 
temperature), and water quenched. Quenched samples were then sectioned, grinded, and polished.

Specimens for sintering experiments were made by either a dry mixing or a wet chemistry method. In the dry mixing method, 4 mol. $\% \mathrm{CuO}$ powder were mixed with rutile-phase $\mathrm{TiO}_{2}$. In the wet chemistry method, an appropriate amount of $\mathrm{Cu}\left(\mathrm{NO}_{3}\right)_{2} \cdot 2.5 \mathrm{H}_{2} \mathrm{O}(99.99 \%$, purchased from Sigma-Aldrich) was dissolved in DI water to make an aqueous $\mathrm{Cu}^{2+}$ solution. Subsequently, rutile $\mathrm{TiO}_{2}$ nanopowder was impregnated in the $\mathrm{Cu}^{2+}$ solution. The mixtures were then dried in an oven at $85^{\circ} \mathrm{C}$ for 12 hours. The dried powders were ground in a mortar for 10 minutes, followed by annealing in air at $500^{\circ} \mathrm{C}$ for 1 hour (to decompose $\mathrm{Cu}\left(\mathrm{NO}_{3}\right)_{2}$ into $\mathrm{CuO}$, which occurs at $\sim 180^{\circ} \mathrm{C}$ ). After annealing, the powders were ground for another 10 minutes. The final powders (made by the either method) were uniaxially pressed at 200 MPa to make green pellets of $6.35 \mathrm{~mm}$ in diameter. The surfaces were slightly grinded to remove contamination from the dies. Green densities of the pellets were measured to be $\sim 40 \%$. Linear shrinkages of compacted pellets were measured by a dilatometer (DIL, NETZSCH Group) up to $1000^{\circ} \mathrm{C}$ at a constant heating ramping rate of $5^{\circ} \mathrm{C} / \mathrm{min}$ in air.

In the second batch of sintering experiments, specimens were isothermally sintered in a muffle furnace (Thermolyne Furnace F6000, Thermo Scientific), for which the temperature profile was carefully calibrated using a second thermocouple before the experiments to ensure the accuracy of temperature controls and measurements (for accurately determining the eutectic temperature). This batch of sintered specimens were quenched in water to preserve the high-temperature GB structures for subsequent HRTEM characterization. The densities of specimens were measured using both the weight/dimension and the Archimedes method.

Microstructures and compositions were characterized by a field-emission, ultra-high resolution scanning electron microscope (UHR SEM, FEI XL30) operating at $10 \mathrm{kV}$, equipped with an Oxford energy-dispersive X-ray spectroscopy (EDS) analyzer. X-ray diffraction (XRD) experiments were conducted using a Rigaku Ultima IV diffractometer ( $\mathrm{Cu} \mathrm{K \alpha}$ radiation). 
Transmission electron microscopy (TEM) samples were prepared using a focused ion beam (FIB, FEI Scios DualBeam). Atomic-level GB structures were characterized by HRTEM using a FEI Titan microscope operating at $300 \mathrm{kV}$.

\section{Results}

\subsection{Determination of Eutectic Temperature and Composition}

SEM images of $\mathrm{CuO}+20 \mathrm{~mol} . \% \mathrm{TiO}_{2}$ specimen (that was a near-eutectic composition selected for the initial experiment $v s$. the actual eutectic composition was subsequently measured to be $\sim 83 \mathrm{CuO}: 17 \mathrm{TiO}_{2}$ ) after annealing at $1020^{\circ} \mathrm{C}$ for 0.5 hour are shown in Fig. 1; here, a eutectic structure, in which the light-contrast rods were homogeneously embedded in a dark-contrast matrix, can be clearly seen. In contrast, Fig. 2 shows the microstructure and elemental mappings of a $\mathrm{CuO}+20 \mathrm{~mol} \% \mathrm{TiO}_{2}$ (rutile) specimen after annealed at a slightly lower temperature of $1000^{\circ} \mathrm{C}$ for 8 hours, where a similar eutectic structure clearly did not form. The corresponding EDS mappings revealed that the light-contrast phase is copper oxide, while the dark-contrast phase is $\mathrm{TiO}_{2}$, with no apparent reaction and virtually no mutual (solid) solubilities. In addition to the SEM images, visual inspection of the specimens also clearly showed the specimen melt at $1020^{\circ} \mathrm{C}$ but not at $1000^{\circ} \mathrm{C}$. These results (Fig. 1 vs. Fig. 2) undoubtedly suggested that the eutectic temperature of $\mathrm{TiO}_{2}-\mathrm{CuO}$ is $1000 \pm 10^{\circ} \mathrm{C}$.

The XRD patterns of the $\mathrm{CuO}+20 \mathrm{~mol} . \% \mathrm{TiO}_{2}$ specimens quenched from $1000^{\circ} \mathrm{C}$ and $1020^{\circ} \mathrm{C}$, respectively, are shown in Fig. 3. Only the two equilibrium $\mathrm{CuO}$ and rutile $\mathrm{TiO}_{2}$ phases were detected from specimens that were annealed at $1000^{\circ} \mathrm{C}$ for 8 hours and water quenched. The $\mathrm{CuO}+20 \mathrm{~mol} . \% \mathrm{TiO}_{2}$ specimen annealed at $1020^{\circ} \mathrm{C}$ melted (into a nearly-eutectic liquid so that we did not anneal it longer to prevent the spreading of the liquid and minimize its reaction with the $\mathrm{Al}_{2} \mathrm{O}_{3}$ crucible), the non-equilibrium $\mathrm{Cu}_{2} \mathrm{O}$ and $\mathrm{Cu}_{3} \mathrm{TiO}_{4}$ phases, as well as the sapphire $\mathrm{Al}_{2} \mathrm{O}_{3}$ impurity phase, were found in the water-quenched specimen (where the crucible was quenched together with the eutectic liquid into the water). 
Further quantitative EDS analysis from multiple measurements of the eutectic structures seen in $\mathrm{SEM}$ showed the average measured composition corresponded to a cation ratio of $\mathrm{Cu}: \mathrm{Ti}=$ $4.95 \pm 0.11$, i.e., the eutectic composition is $\sim 17 \mathrm{~mol} . \% \mathrm{TiO}_{2}+\sim 83 \mathrm{~mol} . \% \mathrm{CuO}$.

\subsection{Sub-Eutectic Activated Sintering}

Fig. 4 shows the linear shrinkage vs. temperature curves of undoped and 4 mol. \% CuO-doped $\mathrm{TiO}_{2}$ (rutile) measured by dilatometry at a constant heating rate of $5^{\circ} \mathrm{C}$ per minute. The doped powders were prepared by either a dry mixing or a wet chemistry method described in the "Experiments" section. At $1000^{\circ} \mathrm{C}$, undoped $\mathrm{TiO}_{2}$ specimen had $\sim 15 \%$ linear shrinkage. In contrast, CuO-doped $\mathrm{TiO}_{2}$ specimens had $\sim 32 \%$ and $\sim 28 \%$ linear shrinkage, respectively, for specimens prepared by the wet chemistry and dry mixing methods, respectively. Both doped $\mathrm{TiO}_{2}$ specimens had $\sim 99 \%$ of the theoretical density after the sintering experiments (including possible extra densification during the cooling in the furnace after the dilatometry experiments). These results clearly demonstrated that the addition of $\mathrm{CuO}$ effectively promoted the densification of rutile $\mathrm{TiO}_{2}$ below the bulk eutectic temperature, where the significant enhanced densifications occurred at $200-300^{\circ} \mathrm{C}$ below the bulk eutectic temperature. The specimen prepared by the wet chemistry method, where the doping was presumably more uniform, exhibited significant enhanced densifications at even lower temperatures (Fig. 4).

To further investigate the sintering mechanism, 4 mol. \% $\mathrm{CuO}$-doped $\mathrm{TiO}_{2}$ specimens were isothermally annealed (sintered) at $800^{\circ} \mathrm{C}, 850^{\circ} \mathrm{C}$, and $900^{\circ} \mathrm{C}$, respectively, for 8 hours and subsequently water-quenched. The microstructures of the fractured surfaces of the sintered specimens are shown in Fig. 5 and the measured grain sizes are shown in Fig. 6. Specifically, Figs. 5(a-f) show the SEM images of sintered $\mathrm{CuO}$-doped $\mathrm{TiO}_{2}$ specimens that were prepared by the wet chemistry method. Low-magnification images show uniform structures and the average grain size increased substantially from $800^{\circ} \mathrm{C}$ to $900^{\circ} \mathrm{C}$. Interestingly, a secondary phase (presumably $\mathrm{CuO}$ ) appeared to wet some triple-grain junctions (with low dihedral angles that, in addition to the nanoscale IGFs at GBs, can also promote sintering and affect microstructural 
development, as reviewed and discussed by Castro and Gouvêa [20]) of the specimen sintered and quenched from $900^{\circ} \mathrm{C}$ (Fig. 5f), but not in those at lower temperatures. Figs. 5(g-i) display high-magnification SEM images of the $\mathrm{CuO}$-doped $\mathrm{TiO}_{2}$ prepared by the dry mixing method, sintered at $800^{\circ} \mathrm{C}, 850^{\circ} \mathrm{C}$, and $900^{\circ} \mathrm{C}$, respectively, for 8 hours, and subsequently water quenched. Substantial neck formation and growth were evident in all sub-eutectic sintered specimens (Fig. 5d-i). Finally, we note that the grain growth followed similar trends for the specimens doped by the wet chemistry and dry mixing routes, both of which contained $4 \mathrm{~mol} . \% \mathrm{CuO}$ and were isothermally annealed at $800-900^{\circ} \mathrm{C}$ for 8 hours (Fig. 6).

\subsection{Stabilization of Liquid-Like GB Complexion Below the Bulk Eutectic Temperature}

Fig. 7 and Fig. 8 display the HRTEM images of representative GBs in 4 mol. \% CuO-doped $\mathrm{TiO}_{2}$ specimens that were equilibrated (by isothermal annealing for 8 hours) at $800^{\circ} \mathrm{C}, 850^{\circ} \mathrm{C}$, and $900^{\circ} \mathrm{C}$, respectively, in a calibrated muffle furnace and subsequently water-quenched. In all cases, the GB planes were carefully oriented to be parallel with the incident electron beam to ensure edge-on conditions. Nanometer-thick, structurally-disordered (liquid-like) IGFs were observed in all specimens quenched from $800^{\circ} \mathrm{C}, 850^{\circ} \mathrm{C}$, and $900^{\circ} \mathrm{C}$ after annealing for 8 hours, at all GBs that were examined. The measured individual and average thicknesses of the IGFs were listed in Table I. Specifically, the average measured thickness of the liquid-like IGFs formed at $800^{\circ} \mathrm{C}$ (and \pm one standard deviation) was $0.70 \pm 0.07 \mathrm{~nm}$, which increased to $0.86 \pm$ $0.06 \mathrm{~nm}$ for the IGFs formed at $850^{\circ} \mathrm{C}$ and $0.98 \pm 0.09 \mathrm{~nm}$ for the IGFs formed at $900^{\circ} \mathrm{C}$. These nanoscale IGFs represent a liquid-like interfacial complexion that is thermodynamically stabilized at the general GBs below the bulk eutectic temperature; this stabilization will be quantitively justified by an interfacial thermodynamic model in $\$ 4.2$ and its roles in activated sintering will be discussed in $\$ 4.3$.

\section{Modeling and Discussion}

\subsection{The $\mathrm{TiO}_{2}-\mathrm{CuO}$ Binary Phase Diagram and Bulk Thermodynamic Function}


In 2001, a binary $\mathrm{TiO}_{2}-\mathrm{CuO}$ phase diagram had been calculated via assuming that the liquid phase is an ideal solution, which produced an eutectic temperature of $919^{\circ} \mathrm{C}$ [14], being substantially lower than the $\sim 1000^{\circ} \mathrm{C}$ eutectic temperature that was later suggested via DSC and TG analysis in 2012 [15] and largely confirmed more directly and accurately by the current study. That diagram reported in 2001 [14] represents the only $\mathrm{TiO}_{2}-\mathrm{CuO}$ phase diagram available in literature and has been widely cited. The more accurate measurements of the eutectic temperature and composition obtained in this study, which were consistent with the independent DSC/TG study in 2012 [15], demand a further assessment (and correction) of that $\mathrm{TiO}_{2}-\mathrm{CuO}$ phase diagram, which will also provide the thermodynamic function of the liquid phase that will be useful for the interfacial thermodynamic model presented and discussed in the following section.

To compute the binary phase diagram, we assume that $\mathrm{CuO}$ and $\mathrm{TiO}_{2}$ are mutually immiscible in the solid states (since no detectable solid solubility was reported in literature, which was also verified by EDX analysis in the current study) and use the solid phases as the reference state. The free energy of the $\mathrm{TiO}_{2}-\mathrm{CuO}$ liquid phase (referenced to the two bulk solid phases) is expressed as a Redlich-Kister polynomial ( $n=0$ and 1 for a subregular solution): $\Delta G^{\mathrm{Liq}}=X_{\mathrm{CuO}}^{\mathrm{Liq}} \Delta G_{\mathrm{CuO}}^{\mathrm{Liq}}+X_{\mathrm{TiO}_{2}}^{\mathrm{Liq}} \Delta G_{\mathrm{TiO}_{2}}^{\mathrm{Liq}}+R T\left(X_{\mathrm{CuO}}^{\mathrm{Liq}} \ln X_{\mathrm{CuO}}^{\mathrm{Liq}}+X_{\mathrm{TiO}_{2}}^{\mathrm{Liq}} \ln X_{\mathrm{TiO}_{2}}^{\mathrm{Liq}}\right)+\sum_{n=0,1} L_{n}\left(X_{\mathrm{CuO}}^{\mathrm{Liq}}-X_{\mathrm{TiO}_{2}}^{\mathrm{Liq}}\right)^{n} X_{\mathrm{CuO}}^{\mathrm{Liq}} X_{\mathrm{TiO}_{2}}^{\mathrm{Liq}}$

where $X_{i}^{L i q}$ is the bulk molar fraction of the $i$ component $\left(i=\mathrm{CuO}, \mathrm{TiO}_{2}\right)$ and $L_{n}^{L i q}$ is the interaction parameters. $\Delta G_{i}^{L i q}$, the bulk molar fraction and free energy of forming the liquid phase from the solid phase of the $i$ component, can be derived as

$$
\Delta G_{i}^{L i q}=\left(T_{i}^{m}-T\right) \Delta S_{i}^{m e l t}+\int_{T_{i}^{m}}^{T} \Delta C_{P(i)} d T-T \int_{T_{i}^{m}}^{T} \frac{\Delta C_{P(i)}}{T} d T
$$

where $T_{i}^{m}$ is the melting temperature, $\Delta S_{i}^{\text {melt }}$ is the molar entropy of fusion (melting), and $\Delta C_{p}=C_{p}^{L i q}-C_{p}^{S o l}$ is the molar heat capacity difference between solid and liquid phases. For 
the $\mathrm{TiO}_{2}-\mathrm{CuO}$ system, these thermodynamic parameters of individual components $\left(\mathrm{TiO}_{2}\right.$ and $\mathrm{CuO})$ were taken from Ref. [14], which were originally obtained from a CRC handbook [21]. Subsequently, we obtained the parameters $L_{0}=8.4 \mathrm{~kJ} / \mathrm{mol}$ and $L_{1}=-13.0 \mathrm{~kJ} / \mathrm{mol}$ by solving two equations: $\Delta G^{L i q}=0$ and $\frac{\partial \Delta G^{L i q}}{\partial X_{C u O}}=0$ to match the experimentally-measured eutectic temperature $\left(T^{\text {Eutectic }}=1010^{\circ} \mathrm{C}\right)$ and composition $\left(X_{\text {CuO }}^{\text {Eutectic }}=0.832\right)$. Here, the liquid phase is a subregular solution ( $L_{\mathrm{n}}=0$ for $n \geq 2$ in the Redlich-Kister polynomial). From the derived thermodynamic function (Eq. (1)), we calculated the binary (bulk) phase diagram for the $\mathrm{TiO}_{2}-\mathrm{CuO}$ system, which is shown in Fig. 9.

We should further note that $\mathrm{CuO}$ reduces to $\mathrm{Cu}_{2} \mathrm{O}$ at $1029^{\circ} \mathrm{C}$ in one-atmosphere air [22] so that the above computation only represents the cases that $\mathrm{CuO}$ would remain stable at high temperatures (achievable at higher $\mathrm{P}_{\mathrm{O}_{2}}$ ). Unfortunately, there is no data available for us to calculate the exact the $\mathrm{TiO}_{2}-\mathrm{CuO}-\mathrm{Cu}_{2} \mathrm{O}$ pseudo-binary phase diagram in one-atmosphere air, but we sketch the possible transitions as the dotted lines in Fig. 9 based the $\mathrm{Cu}_{2} \mathrm{O}-\mathrm{Cu}_{2} \mathrm{O}$ reduction temperature and the melting temperature of $\mathrm{Cu}_{2} \mathrm{O}$, which are the only known points in the $\mathrm{TiO}_{2}-\mathrm{CuO}-\mathrm{Cu}_{2} \mathrm{O}$ phase diagram. Nonetheless, this $\mathrm{Cu}_{2} \mathrm{O}$-to- $\mathrm{Cu}_{2} \mathrm{O}$ reduction occurring at $1029^{\circ} \mathrm{C}$ should not affect the eutectic reaction at $1010^{\circ} \mathrm{C}$ and the stabilization and temperature-dependence of sub-eutectic liquid-like GB complexion (to be discussed in the next section).

\subsection{An Interfacial Thermodynamic Model and the Computed GB $\lambda$ Diagram}

The thermodynamic stability of nanoscale quasi-liquid IGFs (specifically) and GB complexions (in general) have been reviewed [23, 24]. Furthermore, GB $\lambda$ diagrams have been computed and proven useful for predicting trends in activated sintering in (at least) several refractory alloys [25-31]. Here, we made a first successful attempt to extend the prior successes from metallic alloys [25-31] to a ceramic system.

At the length scale of $0.5-5 \mathrm{~nm}$, a phenomenological interfacial thermodynamic model can be 
formulated for premelting-like IGFs in multicomponent ceramics by combining a sharp-interface model of premelting in unary systems [32] and the Clarke model for equilibrium-thickness IGFs $[33,34]$. Here, an IGF in the $\mathrm{TiO}_{2}-\mathrm{CuO}$ is treated as a confined liquid-like interfacial film (a.k.a. a specific 2-D interfacial phase) with modified thermodynamic properties. The excess grand potential as a function of the film thickness $(h)$ can be written as:

$$
\sigma^{x}(h)=2 \gamma_{\mathrm{cl}}+\Delta G_{\mathrm{amorph}}^{(\mathrm{vol})} \cdot h+\sigma_{\text {short-range }}(h)+\sigma_{\mathrm{vdW}}(h)+\sigma_{\text {elec. }}(h)+\ldots,
$$

where $\gamma_{\mathrm{cl}}$ is the crystal-liquid interfacial energy (that is well defined as $h \rightarrow+\infty$ ) and $\Delta G_{\text {amorph }}^{(\mathrm{vol})}$ is the volumetric free energy for forming an undercooling liquid from the equilibrium solid phases. The last three terms are short-range, van der Waals (vdW) dispersion, and electrostatic interfacial interactions, which should all vanish as $h \rightarrow+\infty$ by definition. A premelting-like GB complexion can be stabilized below the bulk eutectic temperature if the energy penalty for forming an undercooled quasi-liquid film (interfacial phase) of thickness $h$ is overcompensated by the reduction in the total (effective) interfacial energy:

$$
-\Delta \gamma \cdot f(h)>\Delta G_{\text {amorph }}^{(v o l)} h
$$

where

$$
\Delta \gamma \equiv 2 \gamma_{\mathrm{cl}}-\sigma^{x}(0)
$$

and $f(h)$ is a dimensionless interfacial coefficient (that varies from $f(0)=0$ to $f(+\infty)=1$ by definition, but not necessarily monotonically), defined as:

$$
f(h)=1+\frac{\left[\sigma_{\text {short-range }}(h)+\sigma_{\text {vdW }}(h)+\sigma_{\text {elec. }}(h)+\ldots\right]}{\Delta \gamma}
$$

The equilibrium thickness, $h_{\mathrm{EQ}}$, corresponds to the minimum of Eq. (3), which implies: 


$$
\left\{\begin{array}{l}
\left.\frac{d \sigma^{x}(h)}{d h}\right|_{h=h_{E Q}}=0 \\
\left.\frac{d^{2} \sigma^{x}(h)}{d h^{2}}\right|_{h=h_{E Q}}>0
\end{array} .\right.
$$

Based on the thermodynamic criterion for stabilizing a sub-eutectic, liquid-like, GB complexion (Eq. (4)), we again adopt (and, in the next step, quantify) a thermodynamic parameter, $\lambda$, to represent the thermodynamic tendency for general GBs to disorder, following earlier studies of metallic alloys [25-31], which is expressed as:

$$
\lambda \equiv \frac{-\Delta \gamma}{\Delta G_{\text {amorph }}^{(\text {vol }}}
$$

To quantify values of $\lambda, \Delta G_{a m o r p h}^{v o l}$, the volumetric free energy penalty of forming an undercooling liquid below eutectic temperature, is expressed as:

$$
\Delta G_{\text {amorph }}^{\text {vol }} \approx \Delta G_{\text {amorph }}^{\text {mol }} /\left[\left(1-X_{\text {CuO }}^{I G F}\right) V_{m\left(T i O_{2}\right)}+X_{\text {CuO }}^{I G F} V_{m(\mathrm{CuO})}\right]
$$

where $X_{\text {CuO }}^{I G F}$ is the average IGF composition and $\Delta G_{\text {amorph }}^{\text {mol }}=\Delta G^{L i q}\left(X_{\text {CuO }}^{I G F}\right)$, which can be calculated using Eq. (1) and the thermodynamic function and data obtained in the prior section for the $\mathrm{TiO}_{2}-\mathrm{CuO}$ liquid phase. Here, the most common and convenient way is to select the $X_{\text {CuO }}^{\mathrm{IGF}}$ that maximizes $\lambda$, as discussed in prior studies of metallic alloys [25-31].

To quantify $\Delta \gamma, \sigma^{x}(0) \equiv \gamma_{G B}^{(0)}$, the average general GB energy of pure $\mathrm{TiO}_{2}$ (with no adsorption), was measured in a prior experiment to be $0.87 \mathrm{~J} / \mathrm{m}^{2}$ [35]. Analogous to both a "macroscopic-atoms" model [36, 37] and a lattice model [38] (with modifications), we estimate the average interfacial energy for the crystal-liquid interface between a pure $\mathrm{TiO}_{2}$ solid and a $\mathrm{TiO}_{2}-\mathrm{CuO}$ binary liquid using the following expression:

$$
\gamma_{c l}=\frac{\Delta H_{T i O_{2}}^{m e l t}}{\kappa m_{1}^{-1} V_{m}^{2 / 3}}+\frac{\Omega_{C u O-T i O_{2}}^{L i q}}{\kappa m_{1}^{-1} V_{m}^{2 / 3}}\left(X_{C u O}^{I G F}\right)^{2}
$$


where the two terms represent the enthalpic (fusion) and chemical (interaction) contributions, respectively, to the crystal-liquid interfacial energy. Here, $\Delta \mathrm{H}_{\mathrm{TiO}_{2}}^{\mathrm{melt}}$ is the molar enthalpy (latent heat) of melting, $\Omega_{\mathrm{CuO}-\mathrm{TiO}_{2}}^{\mathrm{Liq}}=L_{0}$ is the regular-solution parameter for the liquid phase, $V_{m}$ is the molar volume of $\mathrm{TiO}_{2}, \kappa$ is a geometric factor $\left(\kappa \equiv A_{m} / V_{m}^{2 / 3}\right.$, where $A_{m}$ is the area of one mole of molecules spread as a monolayer [38]), and $m_{1}$ is the fraction of bonds across the crystal-liquid interface. The value of $\kappa m_{1}^{-1}$ in Eq. (10) depends on the lattice structure and orientation of the interface and we use $\kappa m_{1}^{-1}=C_{0} \approx 4.5 \times 10^{8}$ to represent the average of different orientations [39] to represent IGFs formed at the average general GBs.

Subsequently, we computed $\lambda$ values and plotted them in the bulk $\mathrm{TiO}_{2}-\mathrm{CuO}$ phase diagram to construct a GB $\lambda$ diagram for $\mathrm{CuO}$-doped $\mathrm{TiO}_{2}$, as shown in Fig. 10, similar to the $\mathrm{GB} \lambda$ diagrams constructed in prior studies for several metallic alloys [25-31]. In the sub-eutectic two-phase region, the computed $\lambda$ increases with increasing temperature, suggesting increasing thermodynamic tendency for average general GBs to disorder that should result in increasing densification rates, consistent with both the intuition and experiments.

A more rigorous and accurate assessment of IGF thickness $\left(h_{\mathrm{EQ}}\right) v s$. temperature requires the quantitative information about the short-range, $\mathrm{vdW}$ dispersion, electrostatic, and any other interfacial interactions in Eq. (3), which is unfortunately not available for the current case of $\mathrm{TiO}_{2}-\mathrm{CuO}$ as well as virtually all other ceramic systems. However, we may adopt a simplified model to justify the observed temperature-dependent IGF thicknesses in the intermediate temperature region (to be defined and discussed subsequently), as follows. First, prior analyses showed that the vdW dispersion interaction, which is always attractive for the IGFs, will be overwhelmed by the $\Delta G_{\text {amorph }}^{\text {vol }}$ term that represents a significantly higher attractive pressure than the vdW dispersion pressure at $\Delta T \equiv T-T^{\text {Eutectic }} \geq 100^{\circ} \mathrm{C}[24,40]$; thus, the vdW dispersion interaction can be neglected well below the eutectic temperature. Moreover, either the short-range or electrostatic interaction can be approximated with an exponentially-decaying form 
(and only one of them likely dominates in a specific ceramic system). Thus, in a simplified model, we can adopt an exponentially-decaying interfacial potential, $f(h)=1-\exp (-h / \xi)$, so that Eq. (3) can be rewritten and simplified to:

$$
\Delta \sigma(h) \equiv \sigma^{x}(h)-\sigma^{x}(0)=\Delta \gamma \cdot f(h)+\Delta G_{\text {amorph }}^{(\mathrm{vol})} \cdot h=\Delta \gamma \cdot[1-\exp (-h / \xi)]+\Delta G_{\text {amorph }}^{(\mathrm{vol})} \cdot h
$$

where $\xi$ is a coherent length [27]. Eq. (11a) can also be rewritten into a dimensionless form:

$$
\frac{\Delta \sigma(h)}{-\Delta \gamma}=\frac{h}{\lambda}+\exp (-h / \xi)-1
$$

Minimizing Eq. (11b) with respective to $h$ produces the equilibrium IGF thickness:

$$
h_{E Q}=\xi \ln (\lambda / \xi)
$$

We should further make two notes. First, Eq. (12) is obtained via assuming a fixed average film composition that maximizes $\lambda$ in Eq. (8). Alternatively, we may minimize Eq. (11a) with respective to both $h$ and $X_{C u O}^{I G F}$. Our numerical analysis showed negligible differences between the calculated " $h$ EQ. $v s . T$ " curves using the two approaches so we choose the simpler approach [by using Eq. (12)]. Second, this simplified model [Eq. (11) and Eq. (12)] can only be used for the intermediate temperature region. On one hand, at higher temperatures $\left(T \sim T^{\text {Eutectic }}\right)$, the divergence of $h_{\mathrm{EQ}}$ predicted from this model should be limited by the attractive vdW dispersion interaction. On the other hand, at lower temperatures, this continuum model is no longer valid when $h_{\mathrm{EQ}}<\sim 0.5 \mathrm{~nm}$ because it does not consider the discrete nature of ion sizes and bond lengths. Nonetheless, this simplified model can be used to justified the measured temperature-dependent IGF thicknesses in the intermediate temperature region of $800-900^{\circ} \mathrm{C}$ for the current case, which is the range of interest for activated sintering.

Specifically, Fig. 11 plots the means and standard deviations of IGF thicknesses measured by HRTEM from specimens equilibrated at $800^{\circ} \mathrm{C}, 850^{\circ} \mathrm{C}$, and $900^{\circ} \mathrm{C}$, along with the computed " $h_{\mathrm{EQ}} v s . T "$ curves for three different selections of the coherent length, $\xi$. The computed " $h_{\mathrm{EQ}} v s$. 
$T^{\prime \prime}$ curve with $\xi=0.38 \mathrm{~nm}$ produced the best fit to the experimental data, while the sensitivity of the different selections of $\xi$ was also tested. Although we do not have the knowledge of the exact value of the coherent length, the value that produced the best fit $(\sim 0.38 \mathrm{~nm})$ is about twice of the $\mathrm{O}-\mathrm{Cu}$ bond length or the size of a $\mathrm{Cu}-\mathrm{O}_{\mathrm{n}}$ polyhedral unit, which appears to be reasonable. Thus, this rather simplified model can justify the stabilization of liquid-like GB complexions below the eutectic temperature as well as the temperature-dependent interfacial widths (the measured " $h_{\mathrm{EQ}}$. $v s . T$ ") observed by HRTEM.

Lastly, we should also recognize the possibility that some of these IGFs exhibit discrete (instead of continuous) thickness (to form Dillon-Harmer GB complexions [23, 41]) for certain specific GBs, e.g., some special GBs with low-index grain surfaces, as shown in a prior study for a (001) // (100) $\mathrm{GB}$ in a $\left(\mathrm{CuO}+\mathrm{SiO}_{2}\right)$ doped $\mathrm{TiO}_{2}$ bicrystal specimen [41]. The origin of the discrete thicknesses and the formation of Dillon-Harmer GB complexions can be explained in the same interfacial thermodynamic framework discussed above via incorporating (adding) an oscillatory structural interaction (as a result of a fixed, finite, atomic size using a hard-sphere approximation) in Eq. (3) or the interfacial coefficient $f(h)[31,41-43]$.

\subsection{Further Discussion of Activated Sintering Mechanisms and Beyond}

The current study measured the eutectic temperature of the $\mathrm{TiO}_{2}-\mathrm{CuO}$ system to be $1010 \pm$ $10{ }^{\circ} \mathrm{C}$ in air, which was higher than that reported in 2001 [14], but similar to that suggested by a DSC and TG study in 2012 [15]. This warrantees our re-assessment and a correction of the $\mathrm{TiO}_{2}-\mathrm{CuO}$ phase diagram reported in Ref. [14] in 2001 based our measured bulk eutectic temperature and composition to compute an improved (corrected) $\mathrm{TiO}_{2}-\mathrm{CuO}$ phase diagram in Fig. 8; this assessment also provided the thermodynamic function for justifying the stabilization of a sub-eutectic liquid-like GB complexion, which leads to enhanced interfacial mass transport and subsequently activated sintering.

The combination of our experimental results undoubtedly demonstrated that the enhanced sintering of $\mathrm{CuO}$-doped $\mathrm{TiO}_{2}$ occurred in the sub-eutectic region, starting at $>300^{\circ} \mathrm{C}$ below the 
bulk eutectic temperature. Thus, this study clearly disapproved the theory that the enhanced sintering in $\mathrm{CuO}$-doped $\mathrm{TiO}_{2}$ at $\sim 850-950^{\circ} \mathrm{C}$ is due to liquid-phase sintering, that was widely assumed in prior studies $[10,12,13]$. Instead, this study strongly suggested, via a combination of HRTEM and thermodynamic modeling, that the addition of $\mathrm{CuO}$ promoted the formation of a liquid-like GB complexion in $\mathrm{TiO}_{2}$ well below the bulk eutectic temperature, which provides a fast mass transport pathway to enhance sub-eutectic densification. After completing all of our experimental and modeling work, we noticed a most-recently published independent study by Paek et al. [44] during the final revision of our manuscript, where the authors also found similar nanoscale IGFs in $\mathrm{CuO}$-doped $\mathrm{TiO}_{2}$ in the temperature range of $850-950^{\circ} \mathrm{C}$ and proposed a similar low-temperature sintering mechanism (without quantitative modeling) [44]. Similar solid-state activated sintering behaviors and mechanisms have also been observed/identified for several ceramic $\left(\mathrm{Bi}_{2} \mathrm{O}_{3}\right.$-doped $\left.\mathrm{ZnO}[16]\right)$ and metallic (Ni-doped $\mathrm{W}$ and $\mathrm{Mo}$ [17-19]) systems.

We should recognize that observing the formation of premelting like IGFs (Figs. 7 and 8) at the same temperature range of sub-eutectic activated sintering (Figs. 4 and 5) is a very strong suggestion, yet not a direct proof, of the proposed mechanism of enhanced sintering in $\mathrm{CuO}$-doped $\mathrm{TiO}_{2}$. Thus, we should further discuss alternative mechanisms that may enhance sintering below the eutectic temperatures. Specifically, a recent study by $\mathrm{Wu}$, Dholabhai, Uberuaga, and Castro showed that the reduction of $\mathrm{Mn}$ cations from $3+$ to $2+$ in $\mathrm{Mn}$-doped $\mathrm{CeO}_{2}$ can result in significant coarsening [45]. In Mn-doped $\mathrm{CeO}_{2}, \mathrm{Mn}$ inhibited grain growth/coarsening below $800^{\circ} \mathrm{C}$ and this inhibition effect became ineffective at $>800^{\circ} \mathrm{C}$ due to reduction of $\mathrm{Mn}$ [45]. In the current study, adding $\mathrm{CuO}$ promoted sintering at all temperatures $\left(\sim 600-1000^{\circ} \mathrm{C}\right)$ as compared with pure $\mathrm{TiO}_{2}$ (Fig. 4) with only moderate (not discontinuous) grain growth/coarsening (Fig. 6); thus, the same mechanism proposed for $\mathrm{Mn}$-doped $\mathrm{CeO}_{2}$ cannot apply directly. Yet, we recognize other possible doping or reduction effects that change the defect concentrations either at interfaces or in the bulk phase, which may subsequently change the sintering rates by changing the bulk or interfacial ion/mass transport rates. In the current case, $\mathrm{CuO}$ can be reduced to $\mathrm{Cu}_{2} \mathrm{O}$ at $\sim 1029^{\circ} \mathrm{C}$ [22] (with some partial reduction starts at 
$\sim 1000^{\circ} \mathrm{C}$ in the $\mathrm{CuO}-\mathrm{TiO}_{2}$ binary system as shown in an earlier study [15]), whereas the enhanced densification occurred at much lower temperatures (as low as 700-900 ${ }^{\circ}$; Figs. 4 and 5). Thus, it is unlikely that the reduction of $\mathrm{Cu}$ played a major role in enhancing sintering at sub-eutectic temperatures $\left(\sim 700-1000^{\circ} \mathrm{C}\right)$ in the current case of $\mathrm{CuO}$-doped $\mathrm{TiO}_{2}$.

Moreover, IGFs should form quickly enough to enable the promotion of densification in the initial stage of sintering, which is possible due to the typical fast surface and GB diffusion rates at such temperatures; this is even easier to be realized in specimens prepared by the wet chemistry route where $\mathrm{CuO}$ could spread on the surfaces on $\mathrm{TiO}_{2}$ particles upon annealing at $500^{\circ} \mathrm{C}$, similar to those demonstrated in various supported (monolayer) oxide catalysts and other (nanoscale) surface phases [46-49]. Specifically, a most-recently published independent study by Paek et al. [44] also showed the formation of IGFs in earlier stages (e.g., after annealing at $850^{\circ} \mathrm{C}$ for 1 hour) in $\mathrm{CuO}$-doped $\mathrm{TiO}_{2}$. The time that is needed for forming IGFs, which presumably enhance sintering subsequently, can also explain the observed result that the densification rates in specimen prepared by the wet chemistry route were higher than those made by the dry mixing method at low temperatures (particularly in $\sim 650-800^{\circ} \mathrm{C}$, as shown in Fig. 4 ).

The thermodynamic stabilization of nanometer-thick quasi-liquid IGFs below eutectic temperature in $\mathrm{CuO}$-doped $\mathrm{TiO}_{2}$ has been well justified by estimating relative interfacial energies via both experimental data and a statistical model as well as quantifying free-energy penalty for forming undercooled liquids using CALPHAD data. Subsequently, an interfacial thermodynamic model is used to justify the temperature-dependent interfacial width.

Following the earlier successes of constructing GB $\lambda$ diagrams to predict useful trends in high-temperature GB disordering and to subsequently forecast activated sintering behaviors (and potentially other materials properties such as creep resistance) in several W- and Mo based metallic alloys [25-31] (as well as more rigorous computed GB complexion diagrams with well-defined transition lines, such as that for Bi-doped $\mathrm{Ni}$ in a most recent report [50]), this study made a first successful attempt to extend the model and method to compute the first GB $\lambda$ 
diagram for a ceramic system $\left(\mathrm{CuO}\right.$-doped $\left.\mathrm{TiO}_{2}\right)$. In future studies, similar or more rigorous "GB diagrams" should be developed for other ceramic systems, which can have broad applications. This is in part because this class of nanoscale IGFs are more ubiquitous and technologically-important for ceramics than metals in general. Furthermore, it is worth noting that nanometer-thick IGFs investigated in this study only represent one of several types of GB complexions discovered recently [23, 51-53]; such GB complexions (a.k.a. interfacial phases that are thermodynamically 2-D) exist ubiquitously in both metallic and ceramic materials, where they can often critically influence or even control a board range of transport, mechanical, and physical properties [23, 25, 27, 43, 51, 54-71] beyond sintering.

\section{Conclusions}

The eutectic temperature of the $\mathrm{CuO}-\mathrm{TiO}_{2}$ system has been determined to be $1010 \pm 10^{\circ} \mathrm{C}$ and the eutectic composition was measured to be $\sim 17 \mathrm{TiO}_{2}: 83 \mathrm{CuO}$ (or $\sim 17$ mol. $\% \mathrm{TiO}_{2}+\sim 83$ mol. \% $\mathrm{CuO}$ ). Based on the measured eutectic temperature and composition, we computed the binary $\mathrm{TiO}_{2}-\mathrm{CuO}$ phase diagram (representing a significant improvement from, and essentially a correction of, the phase diagram available in literature) and formulated the relevant thermodynamic function. A combination of dilatometry measurements and isothermal sintering experiments unequivocally demonstrated the occurrence of activated sintering in $\mathrm{CuO}$-doped $\mathrm{TiO}_{2}$ at as low as $>300^{\circ} \mathrm{C}$ below the bulk eutectic temperature. HRTEM characterization of well-quenched specimens further revealed the formation of nanometer-thick, liquid-like IGFs. It is likely that the enhanced mass transport in this premelting-like complexion can result in the sub-eutectic activated (enhanced) sintering observed in this system. We further calculated a GB $\lambda$ diagram, for the first time for any ceramic system, to represent the thermodynamic tendency for general $\mathrm{GBs}$ in $\mathrm{CuO}$-doped $\mathrm{TiO}_{2}$ to disorder and used an interfacial thermodynamic model to quantitively explain and justify the stabilization of nanometer-thick, liquid-like IGFs below the bulk eutectic temperature as well as the temperature-dependent IGF thicknesses measured by HRTEM. In future studies, similar or different (more rigorous and sophisticated) types of GB 
diagrams should be computed for other ceramic materials, which can potentially have broad scientific and technological impacts.

We gratefully acknowledge the support from the National Science Foundation under grant no. CMMI-1436305, which supports a fundamental study of sintering of $\mathrm{TiO}_{2}$ based ceramics. N.Z., M.Q. and J.L. also acknowledge partial support from a Vannevar Bush Fellowship sponsored by the Basic Research Office of the Assistant Secretary of Defense for Research and Engineering and funded by the Office of Naval Research through grant N00014-16-1-2569 for computing interfacial phase diagrams. 
Table I. Measured IGF thicknesses of 4 mol. \% $\mathrm{CuO}$-doped $\mathrm{TiO}_{2}$ specimens equilibrated (isothermally annealed for $8 \mathrm{~h}$ ) at $800^{\circ} \mathrm{C}, 850^{\circ} \mathrm{C}$, and $900^{\circ} \mathrm{C}$ for 8 hours and water-quenched. Three general GBs were measured for each of three specimens. For each of the nine GBs, the IGF thicknesses were measured at 10 different locations; the mean and standard deviations (that represent the uniformities of IGF thicknesses along the individual GBs) were reported.

\begin{tabular}{|c|c|c|c|c|c|c|c|c|c|}
\hline Specimens & & $800^{\circ} \mathrm{C}$ & & & $850^{\circ} \mathrm{C}$ & & & $900^{\circ} \mathrm{C}$ & \\
\hline $\begin{array}{l}\text { Measured } \\
\text { Thickness of }\end{array}$ & GB \#1 & GB \#2 & GB \#3 & GB \#1 & GB \#2 & GB \#3 & $\mathrm{GB} \# 1$ & GB \#2 & GB \#3 \\
\hline Individual IGFs & 0.68 & 0.69 & 0.75 & 0.89 & 0.82 & 0.86 & 1.01 & 0.92 & 1.03 \\
\hline$(\mathrm{nm})$ & \pm 0.05 & \pm 0.04 & \pm 0.10 & \pm 0.05 & \pm 0.07 & \pm 0.06 & \pm 0.07 & \pm 0.07 & \pm 0.07 \\
\hline $\begin{array}{c}\text { Mean } \pm 1 \text { St. Dev. } \\
(\mathrm{nm})\end{array}$ & & $0.70 \pm 0.07$ & & & $0.86 \pm 0.06$ & & & $0.98 \pm 0.09$ & \\
\hline
\end{tabular}




\section{List of Figure Captions:}

Fig. 1. SEM images of an $80 \mathrm{~mol} . \% \mathrm{CuO}+20 \mathrm{~mol} . \% \mathrm{TiO}_{2}$ specimen isothermally annealed at $1020^{\circ} \mathrm{C}$ for 0.5 hour and water-quenched, showing the formation of a eutectic structure. A quantitative composition analysis of the region highlighted in (b) was performed to measure the eutectic composition (to be $\sim 83 \mathrm{CuO}: 17 \mathrm{TiO}_{2}$ ).

Fig. 2. (a-c) SEM images and (d-f) EDS elemental maps of titanium, copper, and oxygen of an $80 \mathrm{~mol} . \% \mathrm{CuO}+20 \mathrm{~mol} . \% \mathrm{TiO}_{2}$ specimen that was isothermally annealed at $1000^{\circ} \mathrm{C}$ for 8 hours and water-quenched, where a eutectic structure is lacking. The specimens were made by a dry mixture powders; large particles of $\mathrm{CuO}$ remained and the originally-smaller $\mathrm{TiO}_{2}$ particles sintered, whereas no indication of any reaction was evident.

Fig. 3. X-ray diffraction patterns of $80 \mathrm{~mol} . \% \mathrm{CuO}+20 \mathrm{~mol}$. $\% \mathrm{TiO}_{2}$ specimens isothermally annealed and quenched from (a) $1000^{\circ} \mathrm{C}$ and (b) $1020^{\circ} \mathrm{C}$, respectively.

Fig. 4. Linear shrinkage $v$ s. temperature curves of pure $\mathrm{TiO}_{2}$ and $4 \mathrm{~mol}$. \% $\mathrm{CuO}$-doped $\mathrm{TiO}_{2}$ prepared by two different methods (via wet chemistry and dry mixing routes). All powders were uniaxially pressed at $200 \mathrm{MPa}$ and measured using a dilatometer with a constant ramping rate of $5^{\circ} \mathrm{C}$ per minute.

Fig. 5. SEM images of 4 mol. $\% \mathrm{CuO}$-doped $\mathrm{TiO}_{2}$ prepared by two different methods via wet chemistry and dry mixing routes, respectively, isothermally annealed at $800^{\circ} \mathrm{C}, 850^{\circ} \mathrm{C}$, and $900^{\circ} \mathrm{C}$, respectively, for 8 hours, and water-quenched.

Fig. 6. Measured grain sizes of 4 mol. \% $\mathrm{CuO}$-doped $\mathrm{TiO}_{2}$ specimens, made by the wet chemistry (red) and dry mixing (blue) routes, isothermally annealed at $800^{\circ} \mathrm{C}, 850^{\circ} \mathrm{C}$, and $900^{\circ} \mathrm{C}$, 
respectively, for 8 hours, and water-quenched. The grain growth behaviors are similar for specimens doped by two different methods.

Fig. 7. HRTEM images of 4 mol. $\% \mathrm{CuO}$-doped $\mathrm{TiO}_{2}$ specimens isothermally annealed at $800^{\circ} \mathrm{C}$, $850^{\circ} \mathrm{C}$, and $900^{\circ} \mathrm{C}$, respectively, for 8 hours and water-quenched.

Fig. 7. HRTEM images of 4 mol. \% CuO-doped $\mathrm{TiO}_{2}$ specimens equilibrated and quenched at $800^{\circ} \mathrm{C}, 850^{\circ} \mathrm{C}$, and $900^{\circ} \mathrm{C}$, respectively, at a higher magnification.

Fig. 9. Computed $\mathrm{TiO}_{2}-\mathrm{CuO}$ phase diagram of (a) the full composition range and (b) an enlarged section of the $\mathrm{CuO}$-rich region. It should be noted that $\mathrm{CuO}$ is reduced to $\mathrm{Cu}_{2} \mathrm{O}$ at $1029^{\circ} \mathrm{C}$ in air [22] and $\mathrm{CuO}$ would remain stable at higher temperatures only at higher $\mathrm{P}_{\mathrm{O} 2}$. Due to the absence of the $\mathrm{Cu}_{2} \mathrm{O}-\mathrm{TiO}_{2}$ thermodynamic data, we can only calculate the $\mathrm{TiO}_{2}-\mathrm{CuO}$ phase diagram. The dotted lines represent the possible transition lines in air with the $\mathrm{CuO}-\mathrm{Cu}_{2} \mathrm{O}$ transformation, while dashed lines represent the calculated phase transformation lines for the $\mathrm{TiO}_{2}-\mathrm{CuO}$ system assuming no reduction at high temperatures.

Fig. 10. A computed GB $\lambda$ diagram, where the dash lines represent $\lambda=2 \mathrm{~nm}, 4 \mathrm{~nm}$, and $8 \mathrm{~nm}$, respectively, and the color represent the relative thermodynamic tendency for the average general GBs in $\mathrm{CuO}$-doped $\mathrm{TiO}_{2}$ to disorder.

Fig. 11. The average IGF thicknesses vs. equilibration temperatures measured by HRTEM. The three solid lines represent the computed equilibrium thickness ( $h_{\mathrm{EQ}}$.) as functions of temperature with three different coherence lengths $(\xi=0.3 \mathrm{~nm}, 0.38 \mathrm{~nm}$, and $0.5 \mathrm{~nm}$, respectively, where $\xi$ $=0.38 \mathrm{~nm}$ represents the best fit with the experimental data). 


\section{References:}

[1] M. Gratzel, Photoelectrochemical cells, Nature 414(6861) (2001) 338-344.

[2] R. Asahi, T. Morikawa, T. Ohwaki, K. Aoki, Y. Taga, Visible-light photocatalysis in nitrogen-doped titanium oxides, Science 293(5528) (2001) 269-271.

[3] X. Chen, S.S. Mao, Titanium dioxide nanomaterials: Synthesis, properties, modifications, and applications, Chem. Rev. 107(7) (2007) 2891-2959.

[4] F.M. Meng, Influence of sintering temperature on semi-conductivity and nonlinear electrical properties of TiO2-based varistor ceramics, Materials Science and Engineering B-Solid State Materials for Advanced Technology 117(1) (2005) 77-80.

[5] L. Golonka, Technology and applications of low temperature cofired ceramic (LTCC) based sensors and microsystems, Bull Polish Acad Sci Tech Sci 54(2) (2006).

[6] M.T. Sebastian, H. Jantunen, Low loss dielectric materials for LTCC applications: a review, International Materials Reviews 53(2) (2008) 57-90.

[7] E.A. Barringer, H.K. Bowen, FORMATION, PACKING, AND SINTERING OF MONODISPERSE TIO2 POWDERS, Journal of the American Ceramic Society 65(12) (1982) C199-C201.

[8] K.N.P. Kumar, K. Keizer, A.J. Burggraaf, T. Okubo, H. Nagamoto, S. Morooka, DENSIFICATION OF NANOSTRUCTURED TITANIA ASSISTED BY A PHASE-TRANSFORMATION, Nature 358(6381) (1992) 48-51.

[9] S.-H. Yoon, D.-W. Kim, S.-Y. Cho, K.S. Hong, Phase analysis and microwave dielectric properties of LTCC $\mathrm{TiO} 2$ with glass system, Journal of the European Ceramic Society 23(14) (2003) 2549-2552.

[10] J.C. Chang, Y.F. Chen, J.H. Jean, Low-fire processing and dielectric properties of TiO2 with MnOx-CuO, Japanese Journal of Applied Physics Part 1-Regular Papers Short Notes \& Review Papers 43(7A) (2004) 4267-4268.

[11] M. Valant, D. Suvorov, R.C. Pullar, K. Sarma, N.M. Alford, A mechanism for low-temperature sintering, Journal of the European Ceramic Society 26(13) (2006) 2777-2783.

[12] D.W. Kim, T.G. Kim, K.S. Hong, Low-firing of CuO-doped anatase, Materials Research 
Bulletin 34(5) (1999) 771-781.

[13] D.W. Kim, B. Park, J.H. Chung, K.S. Hong, Mixture behavior and microwave dielectric properties in the low-fired $\mathrm{TiO} 2-\mathrm{CuO}$ system, Japanese Journal of Applied Physics Part 1-Regular Papers Short Notes \& Review Papers 39(5A) (2000) 2696-2700.

[14] F.H. Lu, F.X. Fang, Y.S. Chen, Eutectic reaction between copper oxide and titanium dioxide, Journal of the European Ceramic Society 21(8) (2001) 1093-1099.

[15] M.A. de la Rubia, J.J. Reinosa, P. Leret, J.J. Romero, J. de Frutos, J.F. Fernandez, Experimental determination of the eutectic temperature in air of the $\mathrm{CuO}-\mathrm{TiO} 2$ pseudobinary system, Journal of the European Ceramic Society 32(1) (2012) 71-76.

[16] J. Luo, H.F. Wang, Y.M. Chiang, Origin of solid-state activated sintering in Bi2O3-doped $\mathrm{ZnO}$, Journal of the American Ceramic Society 82(4) (1999) 916-920.

[17] X. Shi, J. Luo, Grain boundary wetting and prewetting in Ni-doped Mo, Appl. Phys. Lett. 94(25) (2009) 251908.

[18] V.K. Gupta, D.H. Yoon, H.M. Meyer III, J. Luo, Thin Intergranular Films and Solid-State Activated Sintering in Nickel-Doped Tungsten, Acta Mater. 55 (2007) 3131-3142.

[19] J. Luo, V.K. Gupta, D.H. Yoon, H.M. Meyer, Segregation-Induced Grain Boundary Premelting in Nickel-doped Tungsten, Appl. Phys. Lett. 87 (2005) 231902.

[20] R.H. Castro, D. Gouvêa, Sintering and nanostability: The thermodynamic perspective, J. Am. Ceram. Soc. 99(4) (2016) 1105-1121.

[21] J.F. Shackelford, Y.-H. Han, S. Kim, S.-H. Kwon, CRC materials science and engineering handbook, CRC press2016.

[22] H. Nishiura, R.O. Suzuki, K. Ono, L.J. Gauckler, Experimental phase diagram in the Ag-Cu2O-CuO system, Journal of the American Ceramic Society 81(8) (1998) 2181-2187.

[23] P.R. Cantwell, M. Tang, S.J. Dillon, J. Luo, G.S. Rohrer, M.P. Harmer, Overview No. 152: Grain boundary complexions, Acta Mater. 62 (2014) 1-48.

[24] J. Luo, Stabilization of nanoscale quasi-liquid interfacial films in inorganic materials: a review and critical assessment, Crit. Rev. Solid State Mater. Sci. 32(1-2) (2007) 67-109.

[25] N. Zhou, T. Hu, J. Luo, Grain boundary complexions in multicomponent alloys: Challenges and opportunities, Curr. Opin. Solid State Mater. Sci. 20 (2016) 268-277. 
[26] N. Zhou, J. Luo, Developing grain boundary diagrams for multicomponent alloys, Acta Mater. 91 (2015) 202-216.

[27] J. Luo, Developing Interfacial Phase Diagrams for Applications in Activated Sintering and Beyond: Current Status and Future Directions, J. Am. Ceram. Soc. 95(8) (2012) 2358-2371.

[28] X. Shi, J. Luo, Developing grain boundary diagrams as a materials science tool: A case study of nickel-doped molybdenum, Phys. Rev. B 84(1) (2011) 014105.

[29] X. Shi, J. Luo, Decreasing the Grain Boundary Diffusivity in Binary Alloys with Increasing Temperature, Phys. Rev. Lett. 105 (2010) 236102.

[30] J. Luo, X.M. Shi, Grain boundary disordering in binary alloys, Appl. Phys. Lett. 92 (2008 ) 101901

[31] J. Luo, Liquid-like interface complexion: From activated sintering to grain boundary diagrams, Curr. Opin. Solid State Mater. Sci. 12(5/6) (2008) 81-88.

[32] J.G. Dash, A.M. Rempel, J.S. Wettlaufer, The Physics of Premelted Ice and Its Geophysical Consequences, Reviews of Modern Physics 78 (2006) 695-741.

[33] D.R. Clarke, T.M. Shaw, A.P. Philipse, R.G. Horn, Possible Electrical Double-Layer Contribution to the Equilibrium Thickness of Intergranular Glass Films in Polycrystalline Ceramics, J. Am. Ceram. Soc. 76 (1993) 1201-04.

[34] D.R. Clarke, On the Equilibrium Thickness of Intergranular Glass Phases in Ceramic Materials, J. Am. Ceram. Soc. 70(1) (1987) 15-22.

[35] R.H.R. Castro, B.B. Wang, The Hidden Effect of Interface Energies in the Polymorphic Stability of Nanocrystalline Titanium Dioxide, Journal of the American Ceramic Society 94(3) (2011) 918-924.

[36] L.P.H. Jeurgens, Z. Wang, E.J. Mittemeijer, Thermodynamics of reactions and phase transformations at interfaces and surfaces, International Journal of Materials Research 100(10) (2009) 1281-1307.

[37] R. Benedictus, A. Böttger, E.J. Mittemeijer, Thermodynamic model for solid-state amorphization in binary systems at interfaces and grain boundaries, Phys Rev B 54(13) (1996) 9109-9125.

[38] N. Eustathopoulos, M. Nicholas, B. Drevet, Wettabilty At High Temperatures Pergamon, 
Amsterdam, 1999.

[39] H. Bakker, Enthalpies in alloys, Miedema's semi-empirical model, Trans. Tech. Publications (1998) 1-78.

[40] J. Luo, Y.-M. Chiang, Existence and Stability of Nanometer-thick Disordered Films on Oxide Surfaces, Acta Mater. 48(18-19) (2000) 4501-4515.

[41] S. Ma, P.R. Cantwell, T.J. Pennycook, N. Zhou, M.P. Oxley, D.N. Leonard, S.J. Pennycook, J. Luo, M.P. Harmer, Grain boundary complexion transitions in WO3- and CuO-doped TiO2 bicrystals, Acta Mater. 61(5) (2013) 1691-1704.

[42] J. Luo, Grain boundary complexions: The interplay of premelting, prewetting, and multilayer adsorption, Appl. Phys. Lett. 95(7) (2009) 071911.

[43] S.J. Dillon, M.P. Harmer, J. Luo, Grain Boundary Complexions in Ceramics and Metals: An Overview, JOM 61 [12] (2009) 38-41.

[44] Y.-K. Paek, C.-K. Shin, K.-S. Oh, T.-J. Chung, H.J. Cho, Low-temperature Sintering Behavior of TiO2 Activated with CuO, J. Korean Ceram. Soc 53(6) (2016) 682-688.

[45] L. Wu, P.P. Dholabhai, B.P. Uberuaga, R.H. Castro, Temperature Dependence Discontinuity in the Stability of Manganese doped Ceria Nanocrystals, Cryst. Growth Des. 17 (2017) 446-453.

[46] Y.-C. Xie, Y.-Q. Tang, Spontaneous Monolayer Dispersion of Oxides and Salts onto Surfaces of Supports: Applications to Heterogeneous Catalysis, Adv. Catal. 31 (1990) 1-43.

[47] H. Qian, J. Luo, Nanoscale Surficial Films and A Surface Transition in V2O5-TiO2-Based Ternary Oxide Systems, Acta Mater. 56 (2008) 4702-4714.

[48] H.J. Qian, J. Luo, Vanadia-Based Equilibrium-Thickness Amorphous Films on Anatase (101) Surfaces, Appl. Phys. Lett. 91(6) (2007) 061909.

[49] J. Luo, Y.-M. Chiang, Wetting and Prewetting on Ceramic Surfaces, Annu. Rev. Mater. Res. 38 (2008) 227-249.

[50] N. Zhou, Z. Yu, Y. Zhang, M.P. Harmer, J. Luo, Calculation and validation of a grain boundary complexion diagram for Bi-doped Ni, Scr. Mater. 130 (2017) 165-169.

[51] W.D. Kaplan, D. Chatain, P. Wynblatt, W.C. Carter, A review of wetting versus adsorption, complexions, and related phenomena: the rosetta stone of wetting J. Mater. Sci. 48 (2013) 
$5681-5717$

[52] S.J. Dillon, M. Tang, W.C. Carter, M.P. Harmer, Complexion: A new concept for kinetic engineering in materials science, Acta Mater. 55(18) (2007) 6208-6218

[53] S. Ma, K. Meshinchi Asl, C. Tansarawiput, P.R. Cantwella, M. Qi, M.P. Harmer, J. Luo, A Grain-Boundary Phase Transition in Si-Au, Scr. Mater. 66 (2012) 203-206.

[54] J. Luo, A Short Review of High-Temperature Wetting and Complexion Transitions with a Critical Assessment of Their Influence on Liquid Metal Embrittlement and Corrosion, Corrosion 72(7) (2015) 897-910.

[55] J. Luo, Interfacial engineering of solid electrolytes, Journal of Materiomics 1(1) (2015) 22-32.

[56] J. Luo, H. Cheng, K.M. Asl, C.J. Kiely, M.P. Harmer, The Role of a Bilayer Interfacial Phase on Liquid Metal Embrittlement, Science 333(6050) (2011) 1730-1733.

[57] A. Khalajhedayati, Z. Pan, T.J. Rupert, Manipulating the interfacial structure of nanomaterials to achieve a unique combination of strength and ductility, Nature Communications 7 (2016) 10802.

[58] A. Tewari, P. Bowen, Grain boundary complexion and transparent polycrystalline alumina from an atomistic simulation perspective, Curr. Opin. Solid State Mater. Sci. 20(5) (2016) 278-285.

[59] B.B. Straumal, A.A. Mazilkin, B. Baretzky, Grain boundary complexions and pseudopartial wetting, Curr. Opin. Solid State Mater. Sci. 20(5) (2016) 247-256.

[60] O. Schumacher, C.J. Marvel, M.N. Kelly, P.R. Cantwell, R.P. Vinci, J.M. Rickman, G.S. Rohrer, M.P. Harmer, Complexion time-temperature-transformation (TTT) diagrams: Opportunities and challenges, Curr. Opin. Solid State Mater. Sci. 20(5) (2016) 316-323.

[61] T.J. Rupert, The role of complexions in metallic nano-grain stability and deformation, Curr. Opin. Solid State Mater. Sci. 20(5) (2016) 257-267.

[62] G.S. Rohrer, The role of grain boundary energy in grain boundary complexion transitions, Curr. Opin. Solid State Mater. Sci. 20(5) (2016) 231-239.

[63] J.M. Rickman, J. Luo, Layering transitions at grain boundaries, Curr. Opin. Solid State Mater. Sci. 20(5) (2016) 225-230. 
[64] W. Rheinheimer, M.J. Hoffmann, Grain growth in perovskites: What is the impact of boundary transitions?, Curr. Opin. Solid State Mater. Sci. 20(5) (2016) 286-298.

[65] S.A.E. Johansson, G. Wahnström, First-principles derived complexion diagrams for phase boundaries in doped cemented carbides, Curr. Opin. Solid State Mater. Sci. 20(5) (2016) 299-307.

[66] Q. Gao, M. Widom, Surface and grain boundary complexions in transition metal - Bismuth alloys, Curr. Opin. Solid State Mater. Sci. 20(5) (2016) 240-246.

[67] T. Frolov, M. Asta, Y. Mishin, Phase transformations at interfaces: Observations from atomistic modeling, Curr. Opin. Solid State Mater. Sci. 20(5) (2016) 308-315.

[68] S.J. Dillon, K. Tai, S. Chen, The importance of grain boundary complexions in affecting physical properties of polycrystals, Curr. Opin. Solid State Mater. Sci. 20(5) (2016) 324-335.

[69] G.S. Rohrer, M.P. Martin, Grain boundary complexions - current status and future directions, Curr. Opin. Solid State Mater. Sci. 20(5) (2016) iv-v.

[70] B.B. Straumal, B. Baretzky, Grain Boundary Phase Transitions and their Influence on Properties of Ploycrystals, Interf. Sci. 12 (2004) 147-55.

[71] A. Kundu, K.M. Asl, J. Luo, M.P. Harmer, Identification of a Bilayer Grain Boundary Complexion in Bi-doped Cu, Scr. Mater. 68 (2013) 146-149. 

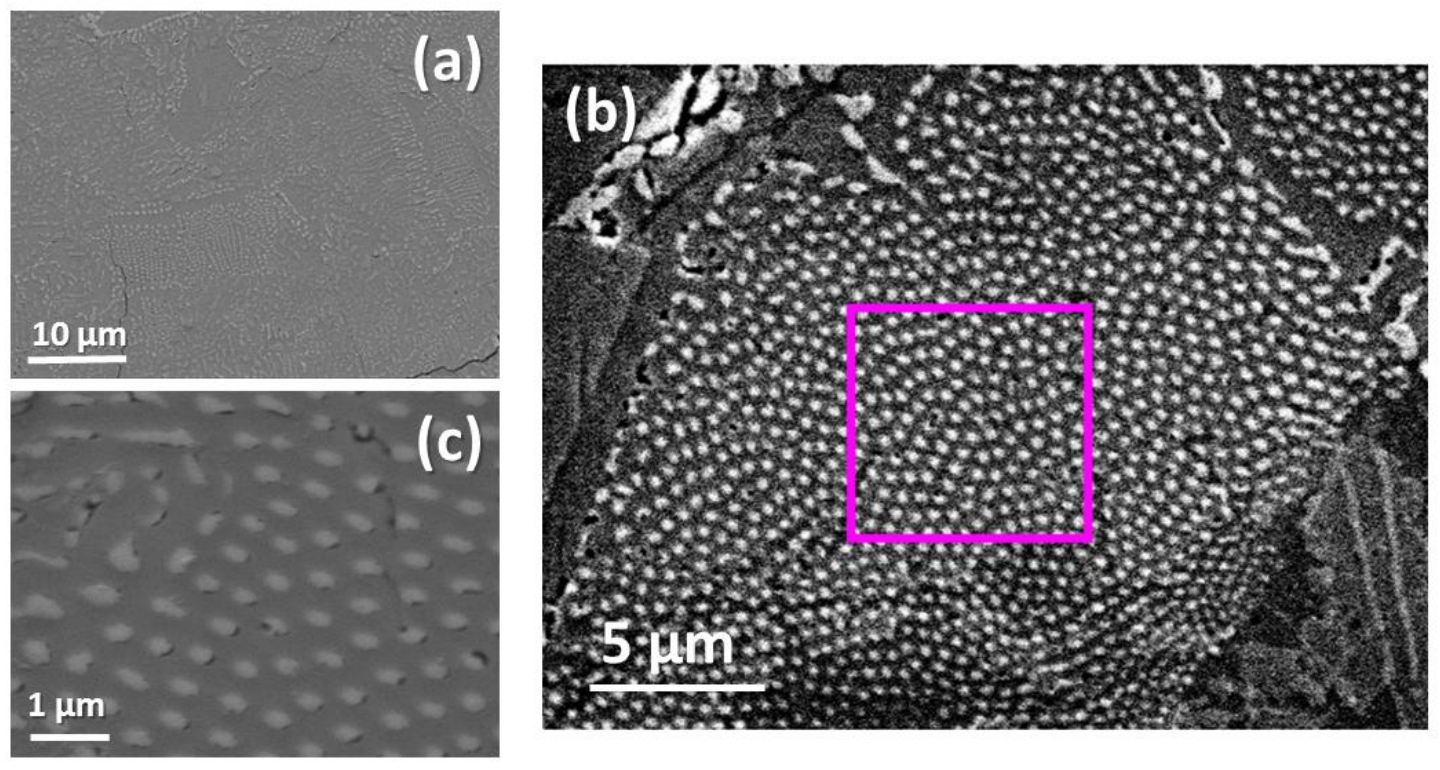

Fig. 1. SEM images of an $80 \mathrm{~mol} . \% \mathrm{CuO}+20 \mathrm{~mol} . \% \mathrm{TiO}_{2}$ specimen isothermally annealed at $1020^{\circ} \mathrm{C}$ for 0.5 hour and water-quenched, showing the formation of a eutectic structure. A quantitative composition analysis of the region highlighted in (b) was performed to measure the eutectic composition (to be $\sim 83 \mathrm{CuO}: 17 \mathrm{TiO}_{2}$ ). 

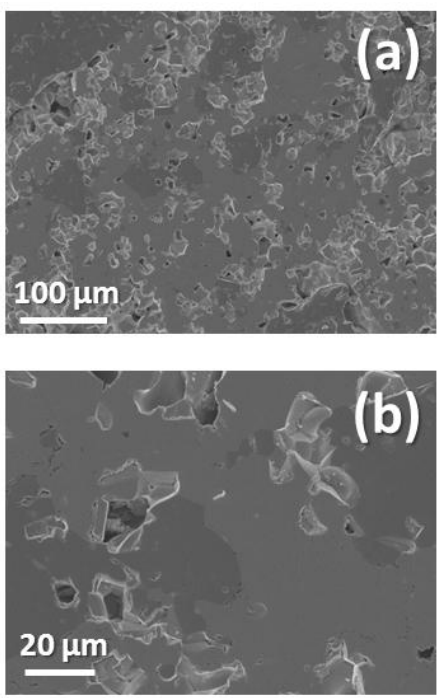
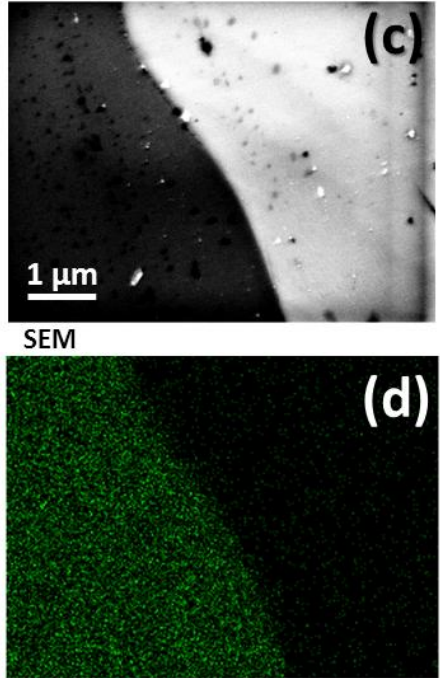

Titanium

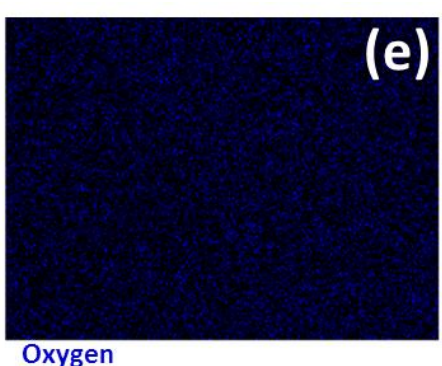

(f)

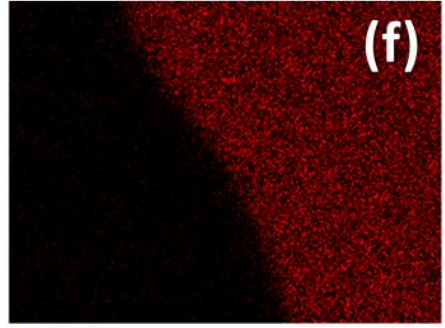

Copper

Fig. 2. (a-c) SEM images and (d-f) EDS elemental maps of titanium, copper, and oxygen of an $80 \mathrm{~mol} . \% \mathrm{CuO}+20 \mathrm{~mol} . \% \mathrm{TiO}_{2}$ specimen that was isothermally annealed at $1000^{\circ} \mathrm{C}$ for 8 hours and water-quenched, where a eutectic structure is lacking. The specimens were made by a dry mixture powders; large particles of $\mathrm{CuO}$ remained and the originally-smaller $\mathrm{TiO}_{2}$ particles sintered, whereas no indication of any reaction was evident. 


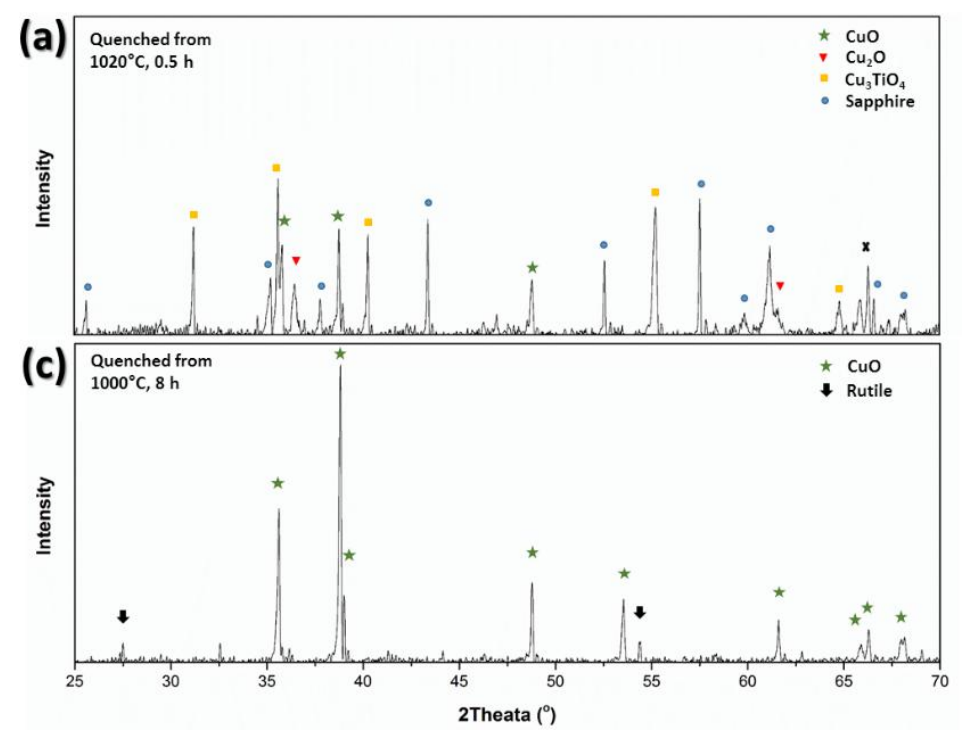

Fig. 3. X-ray diffraction patterns of $80 \mathrm{~mol} . \% \mathrm{CuO}+20 \mathrm{~mol}$. $\% \mathrm{TiO}_{2}$ specimens isothermally annealed and quenched from (a) $1000^{\circ} \mathrm{C}$ and (b) $1020^{\circ} \mathrm{C}$, respectively. 


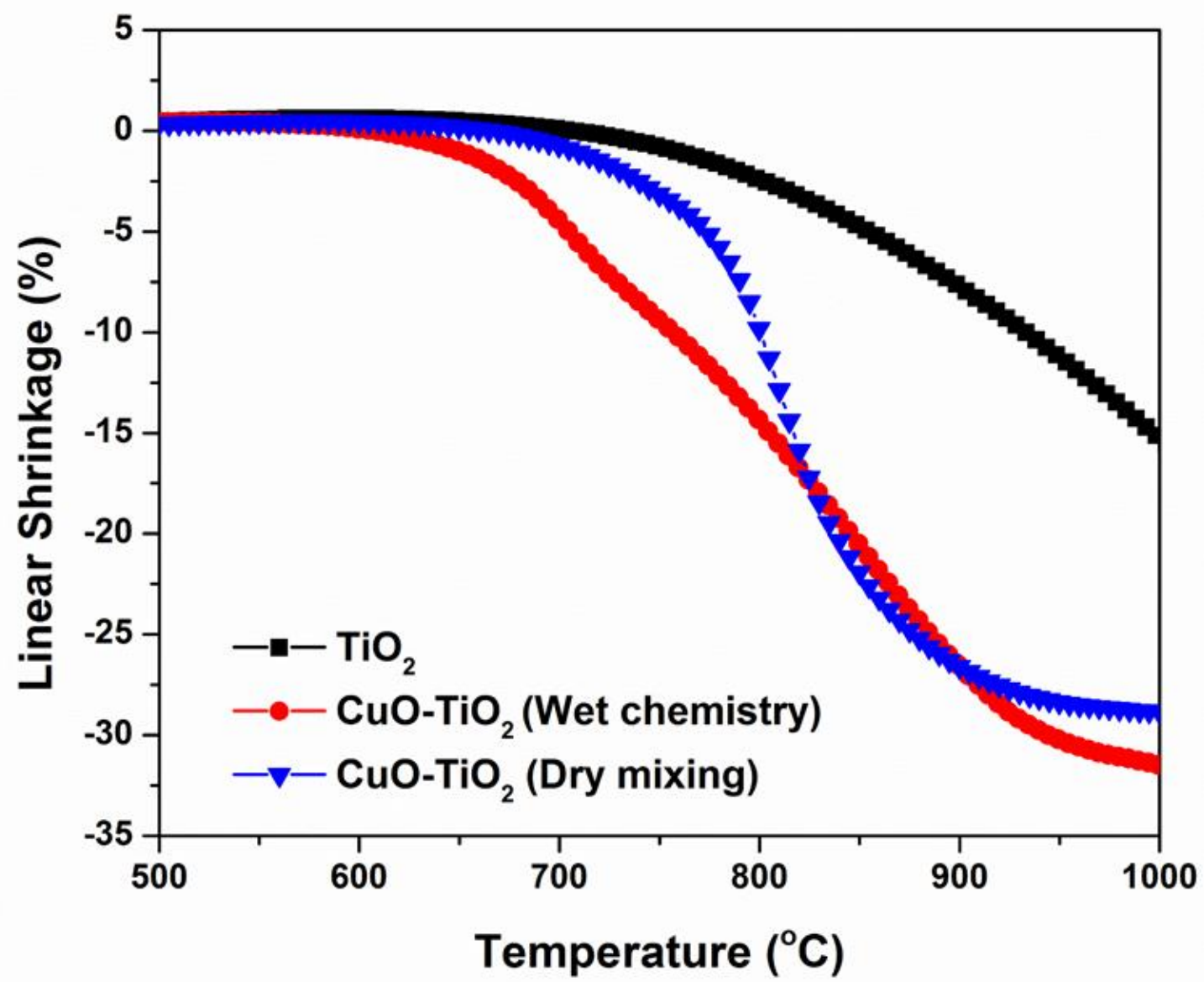

Fig. 4. Linear shrinkage $v$ s. temperature curves of pure $\mathrm{TiO}_{2}$ and 4 mol. $\% \mathrm{CuO}$-doped $\mathrm{TiO}_{2}$ prepared by two different methods (via wet chemistry and dry mixing routes). All powders were uniaxially pressed at $200 \mathrm{MPa}$ and measured using a dilatometer with a constant ramping rate of $5^{\circ} \mathrm{C}$ per minute. 


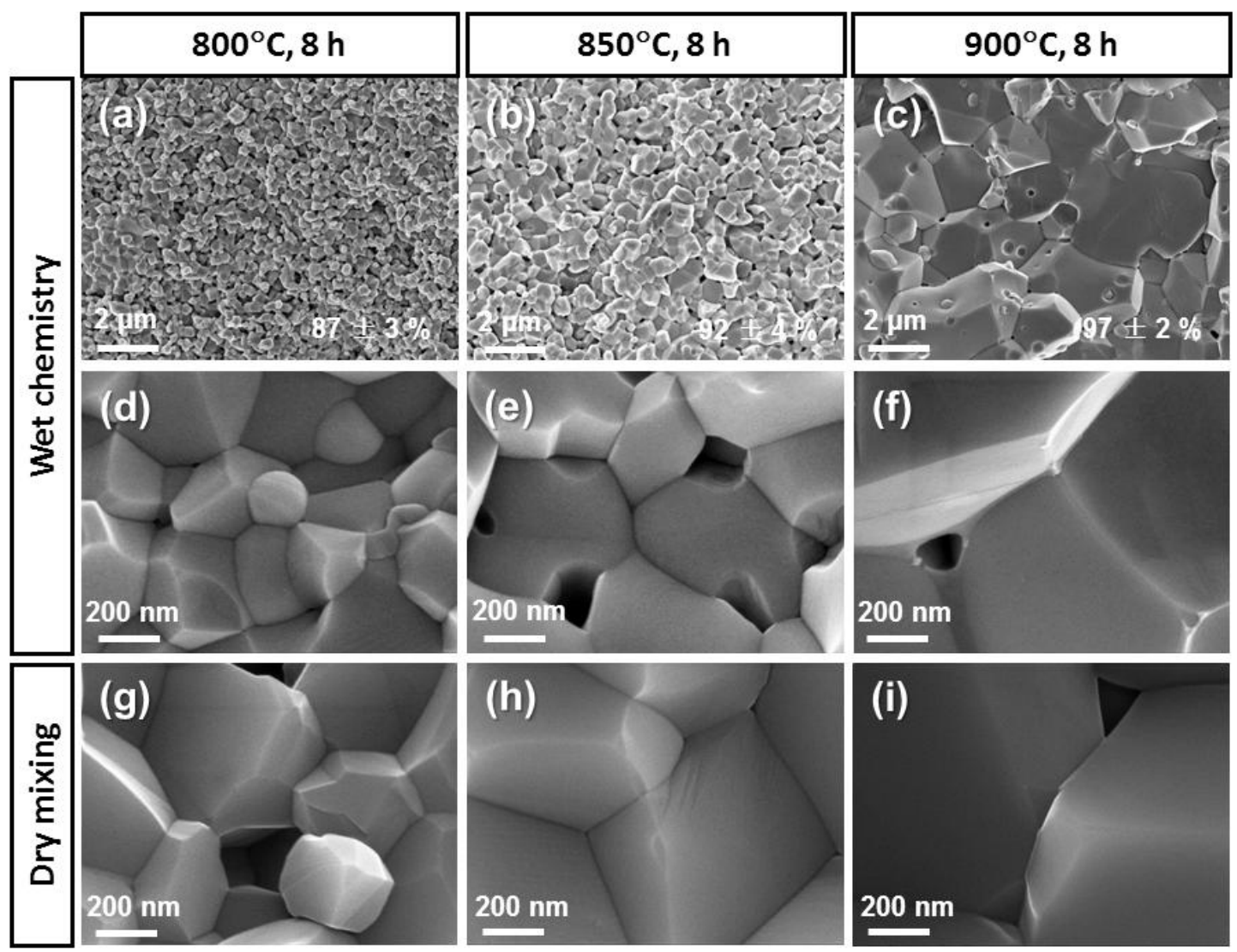

Fig. 5. SEM images of 4 mol. $\% \mathrm{CuO}$-doped $\mathrm{TiO}_{2}$ prepared by two different methods via wet chemistry and dry mixing routes, respectively, isothermally annealed at $800^{\circ} \mathrm{C}, 850^{\circ} \mathrm{C}$, and $900^{\circ} \mathrm{C}$, respectively, for 8 hours, and water-quenched. 


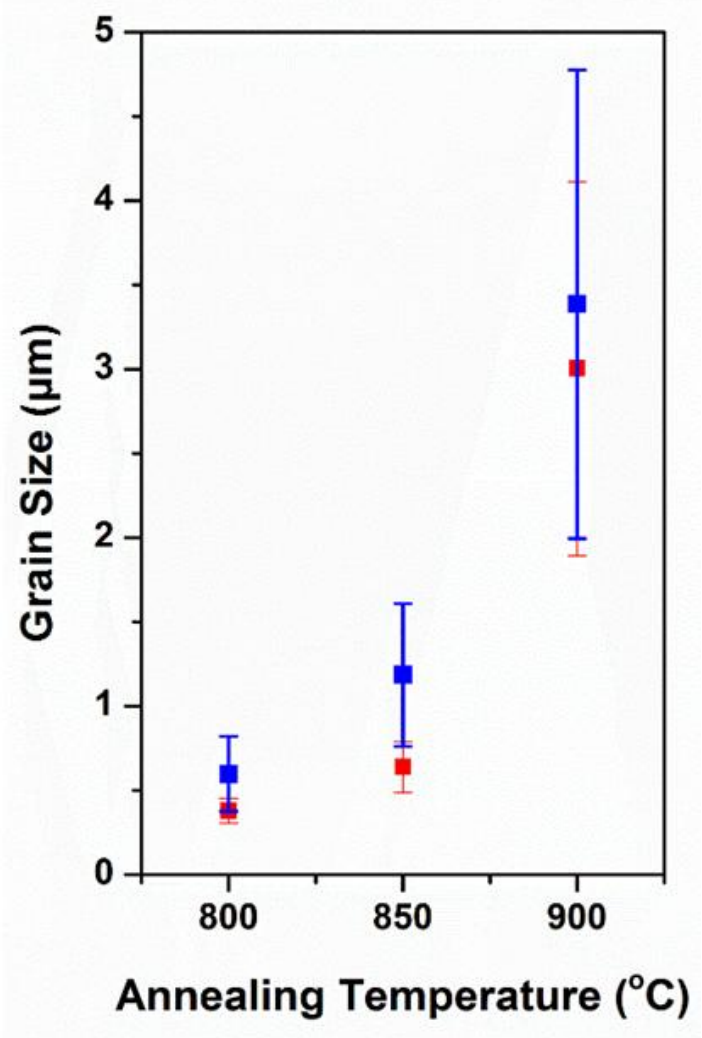

Fig. 6. Measured grain sizes of $4 \mathrm{~mol} . \% \mathrm{CuO}$-doped $\mathrm{TiO}_{2}$ specimens, made by the wet chemistry (red) and dry mixing (blue) routes, isothermally annealed at $800^{\circ} \mathrm{C}, 850^{\circ} \mathrm{C}$, and $900^{\circ} \mathrm{C}$, respectively, for 8 hours, and water-quenched. The grain growth behaviors are similar for specimens doped by two different methods. 


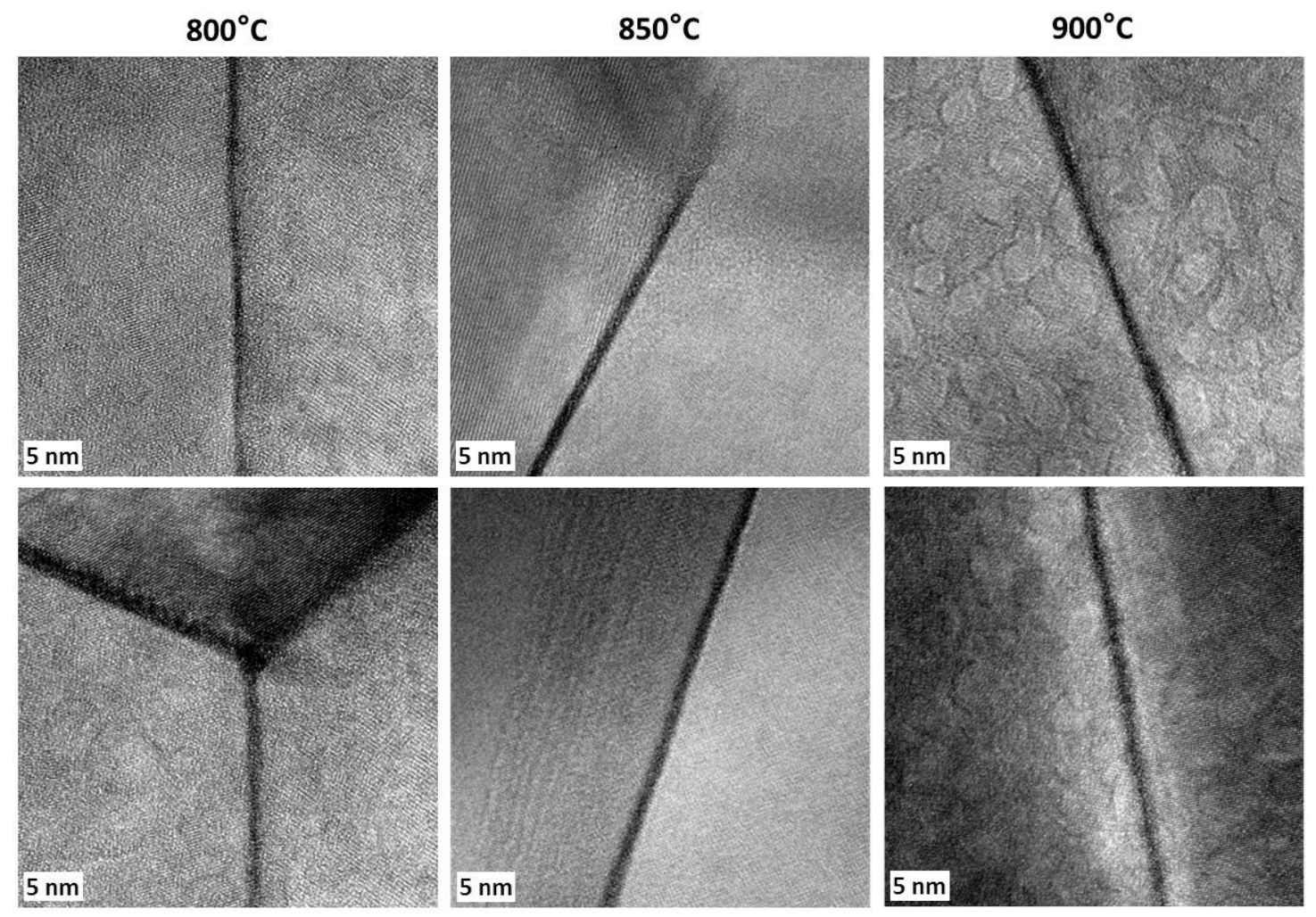

Fig. 7. HRTEM images of $4 \mathrm{~mol}$. \% CuO-doped $\mathrm{TiO}_{2}$ specimens isothermally annealed at $800^{\circ} \mathrm{C}$, $850^{\circ} \mathrm{C}$, and $900^{\circ} \mathrm{C}$, respectively, for 8 hours and water-quenched. 


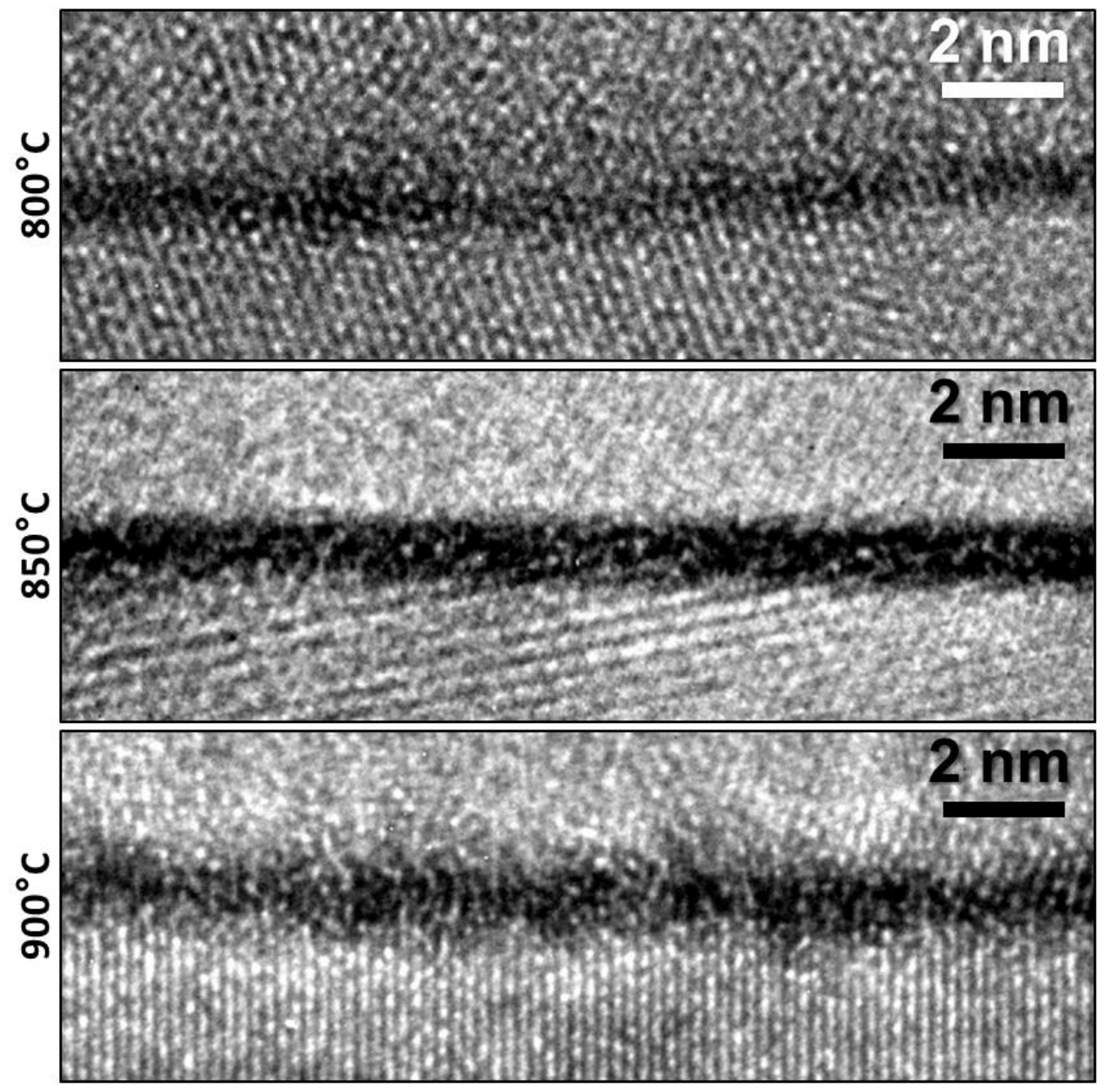

Fig. 7. HRTEM images of 4 mol. \% CuO-doped $\mathrm{TiO}_{2}$ specimens equilibrated and quenched at $800^{\circ} \mathrm{C}, 850^{\circ} \mathrm{C}$, and $900^{\circ} \mathrm{C}$, respectively, at a higher magnification. 
(a)

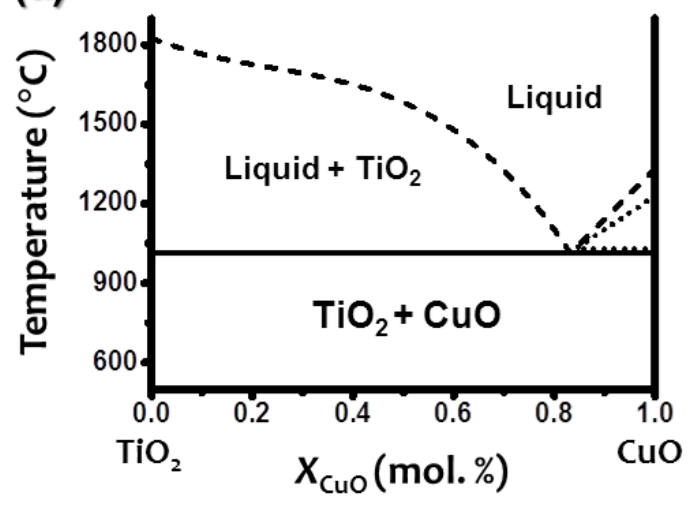

(b)

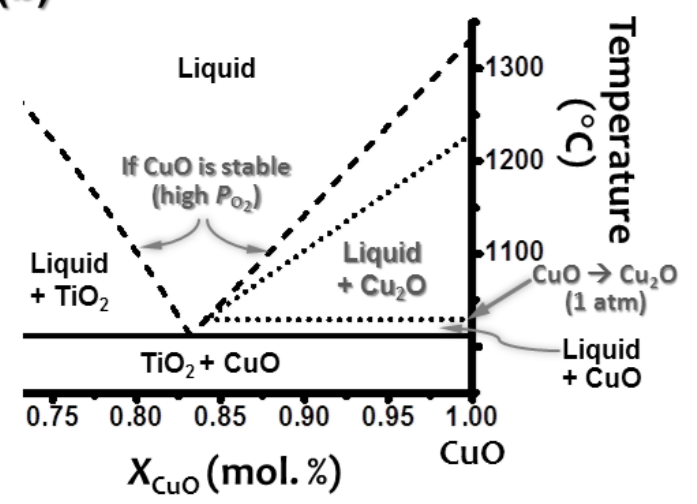

Fig. 9. Computed $\mathrm{TiO}_{2}-\mathrm{CuO}$ phase diagram of (a) the full composition range and (b) an enlarged section of the $\mathrm{CuO}$-rich region. It should be noted that $\mathrm{CuO}$ is reduced to $\mathrm{Cu}_{2} \mathrm{O}$ at $1029^{\circ} \mathrm{C}$ in air [22] and $\mathrm{CuO}$ would remain stable at higher temperatures only at higher $\mathrm{P}_{\mathrm{O} 2}$. Due to the absence of the $\mathrm{Cu}_{2} \mathrm{O}-\mathrm{TiO}_{2}$ thermodynamic data, we can only calculate the $\mathrm{TiO}_{2}-\mathrm{CuO}$ phase diagram. The dotted lines represent the possible transition lines in air with the $\mathrm{CuO}-\mathrm{Cu}_{2} \mathrm{O}$ transformation, while dashed lines represent the calculated phase transformation lines for the $\mathrm{TiO}_{2}-\mathrm{CuO}$ system assuming no reduction at high temperatures. 


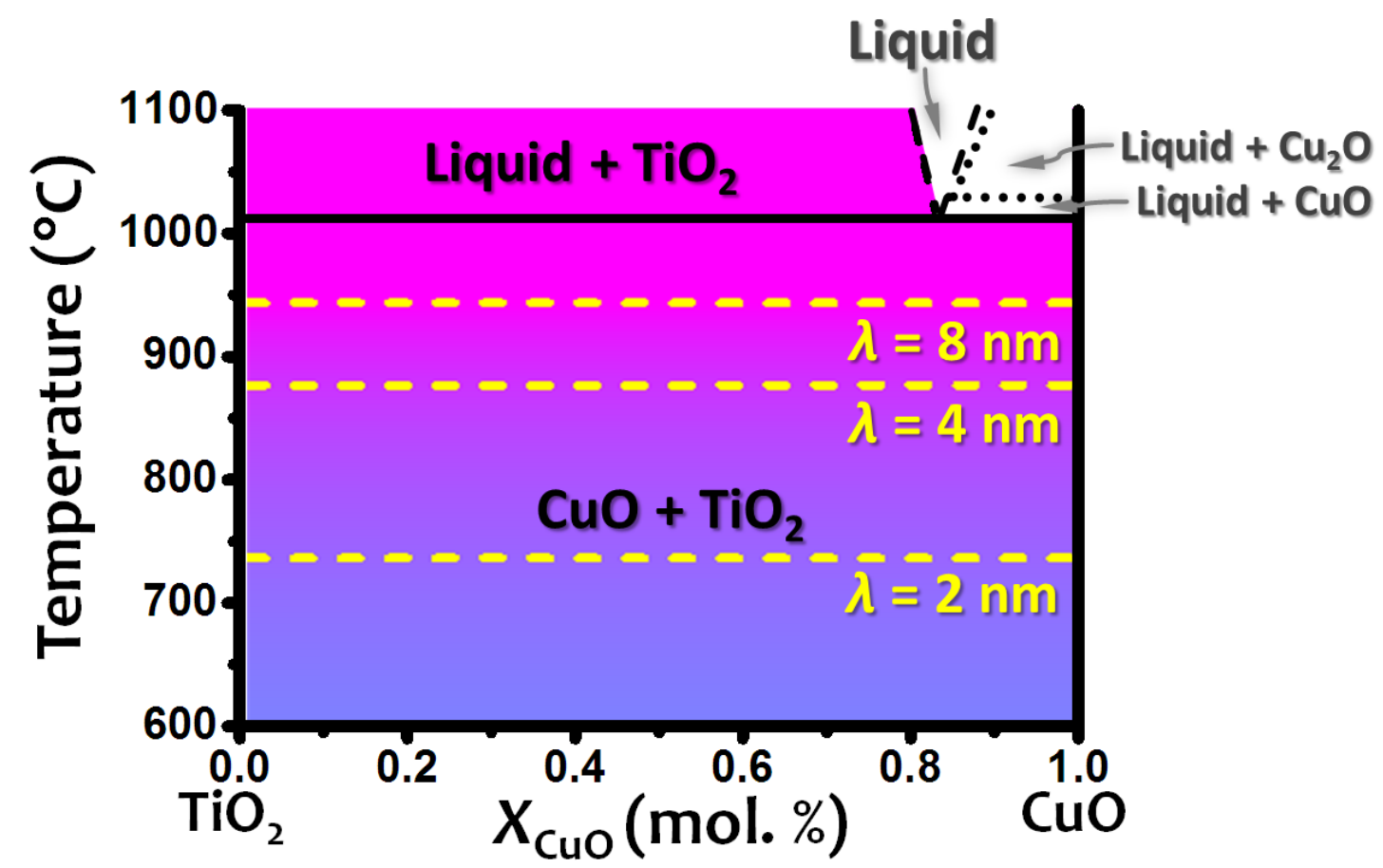

Fig. 10. A computed GB $\lambda$ diagram, where the dash lines represent $\lambda=2 \mathrm{~nm}, 4 \mathrm{~nm}$, and $8 \mathrm{~nm}$, respectively, and the color represent the relative thermodynamic tendency for the average general GBs in $\mathrm{CuO}$-doped $\mathrm{TiO}_{2}$ to disorder. 


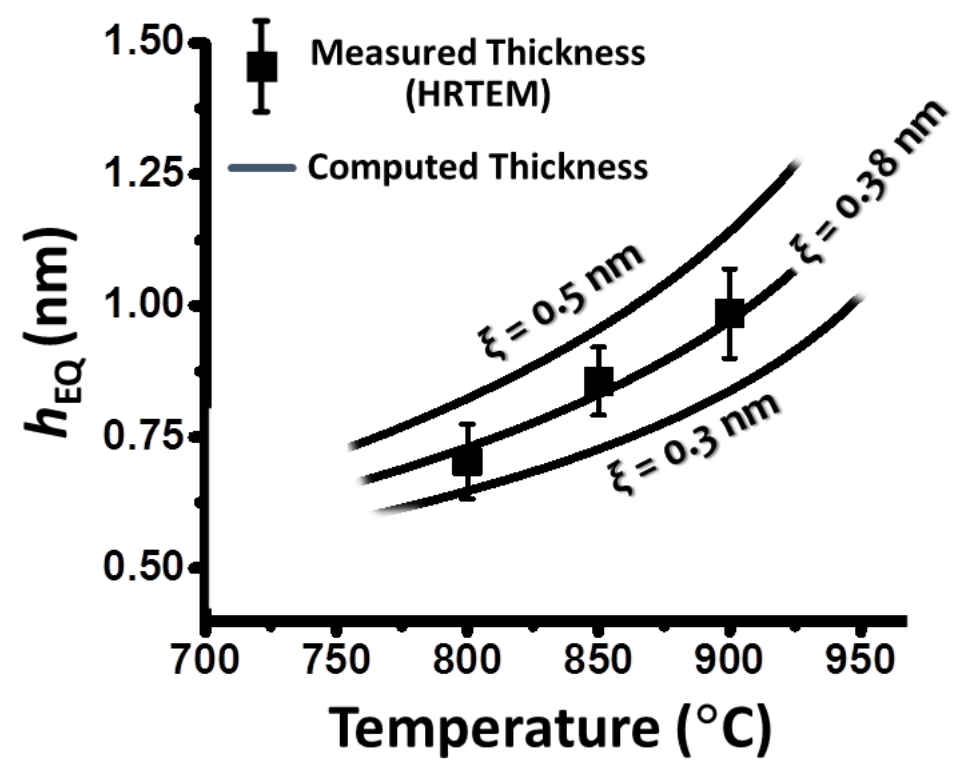

Fig. 11. The average IGF thicknesses $v s$. equilibration temperatures measured by HRTEM. The three solid lines represent the computed equilibrium thickness $\left(h_{\mathrm{EQ}}\right)$ as functions of temperature with three different coherence lengths $(\xi=0.3 \mathrm{~nm}, 0.38 \mathrm{~nm}$, and $0.5 \mathrm{~nm}$, respectively, where $\xi$ $=0.38 \mathrm{~nm}$ represents the best fit with the experimental data). 